\title{
Catalytic insights into the production of biomass-derived side products methyl levulinate, furfural and humins
}

\author{
Layla Filiciotto $^{\mathrm{a}}$, Alina M. Balu ${ }^{\mathrm{a}, *}$, Jan C. Van der Waal ${ }^{\mathrm{b}}$, Rafael Luque ${ }^{\mathrm{a}}$ \\ a Departamento de Quimica Organica, Universidad de Cordoba, Campus de Rabanales, Edificio Marie Curie (C-3), Ctra Nnal IV-A, km 396, Cordoba, Spain \\ ${ }^{\mathrm{b}}$ Avantium Chemicals, Zekeringstraat 29, 1014 BV, Amsterdam, The Netherlands
}

\section{A R T I C L E I N F O}

\section{Article history:}

Received 2 December 2016

Received in revised form 15 February 2017

Accepted 4 March 2017

Available online $\mathrm{xxx}$

\section{Keywords:}

Biomass valorization

Side-products

Methyl levulinate

Furfural

Humins

\begin{abstract}
A B S T R A C T
Biomass conversion into useful chemicals, materials and fuels emerged as a promising alternative toward replacing the current production of most of these commodities and specialty products from petroleum feedstocks. Interestingly, not only end products but also side-products from biomass valorization have a significant potential for future research and further conversion into novel families of useful derivatives. Based on such potential, the proposed contribution has been aimed to focus on catalytic insights into the production of three particular biomass-derived side products from the hemicellulosic fraction, namely methyl levulinate (MeL), Furfural and Humins using both homogeneous and heterogeneously catalyzed processes.
\end{abstract}

(c) 2017 Elsevier B.V. All rights reserved.

\section{Introduction}

Fossil-based resources currently used for energy and material production are not endless and will run out in due time. This ongoing depletion together with the detrimental augmentation of greenhouse effects have driven the worldwide scientific community to find economically valid, environmental-friendly, sustainable alternatives to current petroleum-based industry. Novel routes employing sustainable C-sources will need to be sought, especially in the case of materials and for some types of transportation fuels.

The development of high-output technologies in agronomics [1] has yielded a surplus of one of the most promising undepletable sources: vegetable biomass. In fact, plant-derived feedstocks have been proposed as the major renewable C-source alternative that can matches fossil resources in the chemicals and specific fuels production [2]. The variety of biological and/or chemocatalytic conversion strategies to drop-in fuels, high added value chemicals and novel materials make biomass an attractive and versatile resource [1-5]. In particular, the plentiful abundance of lignocellulosic biomass, along with its potential fast renewability, accommodate the need to find a cheap and readily available green resource.

Lignocellulose is the main structural constituent of all landbased plants [4], found in agricultural and forestry residues,

\footnotetext{
* Corresponding author. Tel.: +34 957211050.

E-mail addresses: qo2balua@uco.es, q62alsor@uco.es (A.M. Balu).
}

herbaceous and woody crops alike. This makes lignocellulosic biomass a readily available non-fossil carbon source without being in competition with the food and feed industries [6]. A clear challenge in the conversion of lignocellulose into valuable-added chemicals relates to its structural complexity. In part, this is due to the nature of the three major components in biomass, namely: (i) lignin (15-30\%) which confers structural rigidity to the plant, comprising a recalcitrant polyaromatic/phenolics polymer; (ii) cellulose (35-50\%), an insoluble, crystalline, linear glucose polymer linked by $\beta-1,4$ glycosidic bonds whose crystallinity gives tensile strength to the plant cell walls; and (iii) hemicellulose (20-35\%), a cross-linked fiberous amorphous polymer, mostly comprised of different pentoses with some hexoses and uronic acids sugar monomers often functionalized with methoxy and acetoxy groups. As a whole feedstock, lignocellulosic biomass can be directly converted into syngas and bio-oil by gasification and pyrolysis [7]. However, more promising routes seem to be the fractionation of lignocellulose into its individual constituents by the means of chemical and/or enzymatic hydrolysis [2,4].

Lignocellulosic biomass can be converted into a plethora of possible compounds, ranging from biofuels to fine chemicals and specialty materials, which include both commercial and unknown compounds [2]. In order to limit the research's targeted molecules, the 2004 US DOE report [8] listed the top biomassderived chemical compounds (later revisited by Bozell and Petersen [9]), which comprised of the 10 most promising compounds that could achieve mass production with the current biorefinery tech- 
nologies. Several new industrial scale productions of biomass derivatives have already been achieved, for example with the two-step acid-catalyzed production of Levulinic Acid (LA) in the socalled Biofine Process [10], which recently has been revitalized by GFBiochemicals. Advancements of Avantium's YXY technology [11] have further plans for large scale production in Antwerp, Belgium for the sustainable conversion of plant-based feedstocks into 2,5furandicarboxylic acid (FDCA), platform chemical for the complete substitution of polluting terephthalate plastics. It is, however, clear from the DoE report and exemplified by these processes that the preferred feedstock for selective chemical production are sugars from the (hemi-)cellulosic fraction of biomass.

Chemocatalytic sugar conversions often leads to numerous sideproducts which limit targeted product yields, increase separation costs and renders overall production uneconomical. Fine-tuning of the current processes with the aim to minimize waste has so far proven difficult, and thus, the valorization of side-products and waste streams has to be studied in depth.

The present contribution aims to provide a general overview of the production of three major products from acid catalyzed sugar conversion processes: Levulinic acid and its Methyl ester (LA, resp., MLA), Furfural (FF), and Humins (HUM). Exploring new ways of their utilization as a feedstock for novel process may lead to improved efficiencies in new biorefinery concepts.

\section{Methyl levulinate}

Levulinate esters are a promising class of biomass derivatives with low toxicity, high lubrification and moderate flow properties at low temperatures [12-15]. Due to their relative simple production, they possess wide application potential as fragrances [16], herbicides [17], cancer therapeutics [18], and as oxygenated additives for gasoline and diesel transportation fuels. In their production, humin formation via polymerization of formed furanic compounds upon hemicellulose dehydration is suppressed at high alcohol/water ratios, making alkyl levulinates a more attractive platform chemical as compared to its hydrolyzed counterpart, levulinic acid.

Methyl levulinate, in particular, is employed as a flavoring agent, and, more importantly, possesses great potential as platform molecule, due to its transformable keto and ester group. Alkyl levulinates may be produced by (i) alcohol esterification of levulinic acid [19], (ii) conversion of furfuryl alcohol and its ethers [20], (iii) alcohol reactive extraction [21-23], (iv) carbohydrates conversion in alcohol media [24], or (v) as a co-product by direct synthesis from biomass (Scheme 1).

For example, methyl levulinate is a side-product to Avantium's methanolic fructose dehydration to 5-methoxymethylfurfural (MMF) [11], as well as a by-product in the aromatic production from liquefaction and fractionation of lignocellulosic biomass under subcritical methanol conditions [25].

\subsection{Homogeneously catalyzed MeL production}

Producing levulinic esters from levulinic acid has been attempted by esterification of levulinic acid, produced from an aqueous product mixture of homogeneously acid-catalyzed conversion of biomass [19] which comprises also furfural, formic acid and the mineral acid catalyst (the latter two catalyze the esterification as well). A summary of the different employed homogeneous catalytic systems for MeL production from various substrates is given in Table 1.

Homogeneous acid catalysts have been extensively used in the synthesis of methyl levulinate. Brønsted acids are known to catalyze fructose dehydration, while aldose isomerization, required
Table 1

Overall comparison of homogeneous catalysts employed in methyl levulinate production.

\begin{tabular}{llllll}
\hline Catalyst & Substrate & $T\left({ }^{\circ} \mathrm{C}\right)$ & $t(\mathrm{~min})$ & Yield (\%) & Refs. \\
\hline $\mathrm{HCl}$ & Glucose & 160 & 150 & 12 & {$[31]$} \\
$\mathrm{H}_{2} \mathrm{SO}_{4}$ & Glucose & 160 & 150 & 13 & {$[31]$} \\
$\mathrm{H}_{2} \mathrm{SO}_{4}$ & Fructose & 160 & 150 & 73 & {$[31]$} \\
$\mathrm{H}_{2} \mathrm{SO}_{4}$ & Cellulose & 183 & 12 & 38 & {$[32,33]$} \\
$\mathrm{H}_{2} \mathrm{SO}_{4}$ & Cellulose & 190 & 300 & 55 & {$[34]$} \\
$\mathrm{H}_{2} \mathrm{SO}_{4}$ & Glucose & 200 & 120 & 49 & {$[32]$} \\
$\mathrm{Al}_{2}\left(\mathrm{SO}_{3}\right)_{4}$ & Glucose & 160 & 150 & 64 & {$[36]$} \\
$\mathrm{Al}_{2}\left(\mathrm{SO}_{3}\right)_{4}$ & Glucose & 200 & 120 & 54 & {$[35]$} \\
$\mathrm{PTSA}_{\mathrm{In}(\mathrm{OTf})_{3}}$ & Cellulose & 180 & 300 & 20 & {$[42]$} \\
$\mathrm{In}(\mathrm{OTf})_{3}+\mathrm{PTSA}$ & Cellulose & 180 & 300 & 52 & {$[42]$} \\
$\mathrm{In}(\mathrm{OTf})_{3}+2-\mathrm{NSA}$ & Cellulose & 180 & 300 & 70 & {$[42]$} \\
\hline
\end{tabular}

when using glucose, is catalyzed by bases or Lewis acids [26-30]. For this reason, mineral acids such as $\mathrm{H}_{2} \mathrm{SO}_{4}$ and $\mathrm{HCl}$ yielded $>70 \%$ methyl levulinate from fructose, but low yields (ca. 12\%) were observed from glucose [31] (Table 1).

As for cellulose, yields of $46 \%$ [32,33] and 55\% of methyl levulinate [34] were obtained in the presence of concentrated sulfuric acid at $179^{\circ} \mathrm{C}$ and in near-critical conditions, respectively. Garves et al. [33] investigated the efficiency of extremely low acid (ELA) concentrations (up to $0.01 \mathrm{~mol} \mathrm{~L}^{-1}$ ), obtaining $49 \%$ methyl levulinate from glucose after $2 \mathrm{~h}$ at $200^{\circ} \mathrm{C}$ at the highest ELA. ELAs were also investigated in the methanolysis of cellulose, yielding $50 \%$ methyl levulinate at $210^{\circ} \mathrm{C}$ using $0.01 \mathrm{~mol} \mathrm{~L}^{-1}$ sulfuric acid.

Homogeneous mixed acids, particularly $\mathrm{Al}_{2}\left(\mathrm{SO}_{4}\right)_{3}$, sparked scientific interest thanks to the co-presence of both Lewis and Brønsted acidity. Yields of 54\% [35] and of 64\% [36] from glucose were reported due to the metal cation ability to catalyze the isomerization of glucose to fructose, and the latter consequent dehydration.

Although high yields might be achieved, homogeneous acid catalysts present major processing drawbacks (e.g. equipment corrosion, inefficient separability and reusability, polluting waste) as well as alcohol dehydration to its diether. A preferential focus was shifted toward heterogeneous catalytic systems.

\subsection{Heterogeneously catalyzed MeL production}

For instance, methyl levulinate yields of $88 \%$ were obtained over a methylated polymer-supported triazene (Me-PST) [36], while $>95 \%$ methyl levulinate yields were achieved in mesoporous structures. In particular, Melero et al. [38] reported a 95\% yield of the levulinate ester in methanol at $117^{\circ} \mathrm{C}$ over SBA-15- $\left(\mathrm{CH}_{2}\right)_{3}-\mathrm{SO}_{3} \mathrm{H}$, which decreased to only $93 \%$ after four consecutive runs. This was attributed to an enhanced mass diffusion of levulinic acid and relative ester in the mesopores. Similar trends were also observed in the use of solid heteropolyacids (HPA). HPA possess higher intrinsic acidity comparable to $\mathrm{H}_{2} \mathrm{SO}_{4}$ but these catalytic systems often display limited surface area and often high solubility in water and/or polar solvents, which leads to leaching of the active phase. The use of a porous catalyst support is often employed in order to avoid these problems. Yields of 73 to $99 \%$ of methyl levulinate were reported for levulinic acid conversion for $\mathrm{H}_{4} \mathrm{SiW}_{12} \mathrm{O}_{40}$ incorporated on mesoporous $\mathrm{SiO}_{2}$ [39] and $\mathrm{H}_{3} \mathrm{PW}_{12} \mathrm{O}_{40}-\mathrm{ZrO}_{2}$ with benzene moieties [40]. The remarkable activity of these catalysts is given by (i) the presence of hydrophobic moieties facilitating faster formation of methyl levulinate thanks to their capacities of facilitating levulinic acid adsorption over $\mathrm{H}_{2} \mathrm{O}$, and (ii) the larger pore structure, rather than acid sites density, type, and activity, factors that in nonporous catalysts (e.g. sulfonated oxides) are key for the observed activity [41]. 


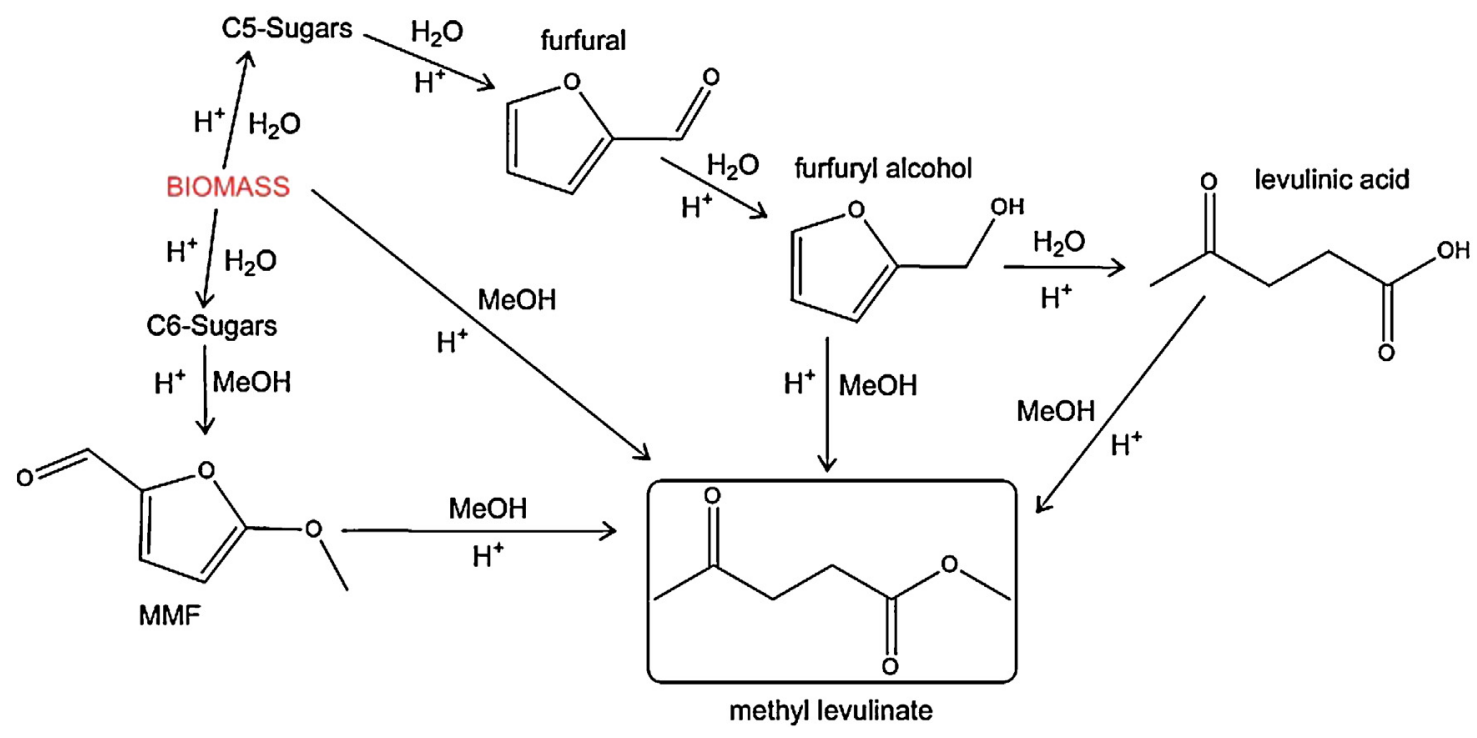

Scheme 1. Different pathways in the formation of methyl levulinate.

Tominaga et al. [42] employed Lewis acid In(OTf $)_{3}$ in combination with Brønsted $p$-toluene sulfonic acid (PTSA) and obtained 70\% methyl levulinate at $180^{\circ} \mathrm{C}$ with an optimum Lewis/Brønsted acid ratio of 0.2 . Substitution of PTSA with 2-naphtalenesulfonic acid improved alkyl levulinate yields to $75 \%$, suggesting that sulfonic acids are highly active in the hydrolysis of cellulose to sugars, while metal triflates catalyze methyl levulinate formation. An optimum acidity (Brönsted + Lewis) was required for these types of reactions. In fact, methyl levulinate yields dropped in pure Brønsted (20\%), or pure Lewis (52\%) acid catalyzed reactions.

Shape selectivity and tunable acidity are well known characteristics of zeolites. Their use as catalysts was investigated in the formation of methyl levulinate from glucose. Conventional zeolites such as H-Beta, H-mordenite, or H-ZMS-5 resulted in lower methyl levulinate yields than those typically reported for their homogeneous counterparts [32]. Only H-USY reported by Saravanamurugan and Riisager [43] yielded 49\% methyl levulinate. Acid site densities of $300 \mu \mathrm{mol} \mathrm{g}^{-1}$ and optimum strong/weak acid ratio of 0.8 (0.3-1.1 range) were best suited for quantitative conversions of glucose into MeL. The same group also reported MeL yields of 13,51 , and $53 \%$ from cellulose, maltose, and cellobiose, respectively. Peng et al. [22] obtained yields of $10,33,43$, and $59 \mathrm{~mol} \%$ of MeL from cellulose, glucose, sucrose, and fructose, respectively, in near-critical methanol using sulfated $\mathrm{TiO}_{2}$ as catalyst, with much reduced yields observed for the use of ZSM-5 (25 and 36), NaY, $\mathrm{H}$-mordenite, sulfated $\mathrm{ZrO}_{2}$, and pristine $\mathrm{TiO}_{2}$ as catalysts. Zeolites performed comparatively worse than sulfated titania (which exhibited mainly strong acid sites) despite their larger amounts of acid sites, stressing the importance of strict catalyst tuning. In addition, 5-methoxymethylfurfural (MMF) and methyl glucosides were found as by products under the investigated reaction conditions.

Recently, zirconia-zeolite hybrid ZrY6(0.5) was found to be remarkably active in the conversion of a variety of substrates, yielding to $68 \%$ methyl levulinate from glucose, $70 \%$ from mannose, $73 \%$ from galactose, $78 \%$ from sucrose, $46 \%$ from cellobiose, and 53 and $27 \%$ from starch and cellulose, respectively[44]. In particular, the acid-base bifunctionality of the catalyst was effective in glucose isomerization and consequent dehydration. Njagi et al. [45] further investigated mesoporous sulfated $\mathrm{TiO}_{2}$-based catalysts, comparing pristine $\mathrm{TiO}_{2}$ and co-precipitated sulfated $\mathrm{TiO}_{2}-\mathrm{ZrO}_{2}$ (TZ) ( $\mathrm{Zr}$ content $=10-50 \%$ ). Sulfated metal oxides with the highest percentage of $\mathrm{Zr}$ exhibited the highest catalytic activity in the production of methyl levulinate in methanol at $200^{\circ} \mathrm{C}$ after $1 \mathrm{~h}$. Significant yields of methyl levulinate were obtained from fructose (71\%), sucrose (54\%) and glucose (23\%). Sulfated TZ50 presented large mesopores that favored internal diffusion. However, the type of acid site types and strength were not reported in this work, perhaps of strong nature due to the claimed low catalyst stability (and the need of thermal treatment for reactivation) probably due to insoluble humins adsorbed on the catalyst surface originated on the strong Brönsted acid sites of the sulfated catalyst. On the other hand, sulfonated carbons derived from biochar have been proven effective in the conversion of polysaccharides, yielding $30 \%$ methyl levulinate [46].

In order to provide environment-friendly and cheap heterogeneous alternatives to those reported, Xu et al. [47] tested inexpensive montmorillonite (MMT) in the conversion of carbohydrates at $200^{\circ} \mathrm{C}$. The highest yield was obtained with $20-\mathrm{SO}_{4}{ }^{2-} / \mathrm{MMT}$, i.e. $65 \%$ methyl levulinate from fructose, while glucose and cellulose conversion yielded 65 and $24 \%$, respectively. A substantial drop in catalytic activity could be observed upon catalyst recycling, with deactivation correlated to humin deposition on catalytic surface. However, calcination treatments were ineffective in recovering any catalytic activity, possibly due to sulfur loss, which, at industrial level, would increase production costs of waste disposal.

$\mathrm{Hu}$ et al. [24] investigated the conversion of levoglucosan in methanol rich medium in order to hinder humins formation, obtaining $>90 \%$ MeL yield, with a ca. $95 \%$ selectivity (while levulinic acid selectivity is attested at $c a$. 25\%). The same group also proposed a reaction mechanism from levoglucosan which undergoes methanolysis to a glucose acetal (methyl $\alpha$-D-glucopyranoside, MGP) at low temperatures $\left(<130^{\circ} \mathrm{C}\right)$, followed by the formation of intermediate 2-(dimethoxymethyl)-5-(methoxymethyl)furan (5-MMF, acetal and ether of HMF) at higher temperatures $\left(150-170^{\circ} \mathrm{C}\right)$, eventually decomposing into methyl formate and levulinate.

A more recent mechanistic study [48] confirmed the reaction pathway proposed by Hu et al. (vide supra) and stressed the influence of Lewis and Brønsted acid sites. In fact, Brønsted acids were further reported to favor methyl glucoside conversion into 5-MMF, while Lewis acids promote the formation of $\mathrm{C}-\mathrm{C}$ cleavage products (e.g. 1,1,2-trimethoxymethane) and prevent further conversion of 5-MMF to MeL [48]. However, Lewis acids promoted cellulose alcoholysis to methyl glucoside, consequently improving overall MeL yields. In conclusion, improved yields of methyl levulinate could 
be achieved utilizing solid acid catalysts featuring (i) fine-tuned Lewis/Brønsted acid sites ratios, (ii) medium strength acid sites, and (iii) regular pore size distribution to avoid diffusional issues.

Promising yields to alkyl levulinates (52\%) could be obtained from furfuryl alcohol conversion in methanol under acidic conditions [49]. Similarly to levulinic acid conversion into its esters, furfuryl alcohol conversion to alkyl levulinates also showed a strong dependence on the accessibility of the reactant to the acid sites rather than acid site strength itself. In fact, acid sites density and strength only play a minor role in the conversion to alkyl esters as compared to substrate internal diffusion limitations, although suitable acid sites must exist.

Yields close to $90 \%$ were recently obtained by preparing $\mathrm{Nb}_{2} \mathrm{O}_{5}$ hybrid bifunctional catalysts containing $\mathrm{H}_{3} \mathrm{PW}_{12} \mathrm{O}_{4}$-type $\mathrm{HPA}$, with phenyl-bridged organosilica moieties [50]. These hybrid catalysts combined hydrophobic moieties and strong Brønsted with moderate Lewis acidities that favored the reaction. Interestingly, the highly ordered structures used in this study showed systematically higher activities with respect to their disordered counterparts.

Hengne et al. [51] also reported the use of functionalized ionic liquids in the alcoholysis of furfuryl alcohol to $\gamma$-valerolactone and alkyl levulinates. In particular, 95\% selectivity to methyl levulinate with $99 \%$ conversion of furfuryl alcohol was given using ionic liquid [BMIM-SH] $\left[\mathrm{HSO}_{4}\right]$. Combination of the latter with $5 \% \mathrm{Ru} / \mathrm{C}$ catalyzed ring cyclization of the alkyl levulinate led to the formation of $\gamma$-valerolactone. Although attractive, this strategy is highly cost ineffective because of the expensive technology currently needed for ionic liquids mass production. Table 2 summarizes a comprehensive overview of results in MeL production reported in this review from different heterogeneous catalysts.

\section{Furfural}

Different from 5-hydroxymethylfurfural (HMF) [52], another member of the furan family (furfural) was identified as one of the top 10 biomass-derived chemicals by the US Department of Energy [8]. First discovered in 1821 by Döbereiner [53], furfural has taken hold of the scientific community as a potential chemical platform, thanks to its high versatility. In fact, furfural (and its derivatives) are highly versatile molecules, finding numerous applications including their use as selective solvent for extractions of conjugated molecules, non-toxic fungicides and nematicides, food and drinks flavor enhancers and as building blocks for transportation fuels, gasoline additives, resins, biopolymers, pharmaceuticals, and similar [54,55].

Furfural has been synthesized both in stand-alone processes from $\mathrm{C} 5$-rich carbohydrates (i.e. xylose, arabinose content in hemi-cellulose [54]) and as a co-product of a variety of biomass valorization processes including the Biofine process for levulinic acid production (vide supra) as well as HMF production via the dehydration of lignocellulosic biomass[56,57]. Current industrial production of furfural involves mineral acid-catalyzed processing of xylose-rich lignocellulosic residues (e.g. bagasse, corn cobs, oat hulls, almond husks) in aqueous media under high steam stripping conditions for product recovery [58,59]. Though this particular process utilizes a green resource, it has significant drawbacks due to equipment corrosion, high amounts of acidic and toxic waste, energy intensiveness, homogeneous catalyst loss, and, last but not least, an elevated number of possible of inevitable side reactions (e.g. degradation, condensation) that generate low value byproducts and limit furfural yields to ca. 50\% [60] (theoretical yield of $73 \mathrm{wt} \%$ from pentose, $64 \mathrm{wt} \%$ from pentosan [61]).

In order to improve operation conditions, a better understanding of the reaction mechanism is required. The mechanism of this dehydration step has not yet been fully elucidated. Owing to dif- ferent reaction pathways proposed, it is still a nowadays matter of debate. Neutral media conversions present low furfural production rates which find a slight increase at the occurrence of autocatalysis by means of the biomass degradation product acetic acid [62], therefore indicating a positive effect of the presence of Brønstedtype acids.

\subsection{Homogeneously catalyzed production of furfural}

Danon et al. [59] extensively addressed mechanistic and kinetics aspects of homogeneous acid catalysis dehydration. Different mechanisms have been proposed for xylose conversion in aqueous acidic media, comprising of open ring enolization or $\beta$-elimination, and cyclic intermediates pathways. In acidic medium such as sulfuric or hydrochloric acid (up to $2.5 \mathrm{wt} \%$ [63]), pentosans hydrolysis comparably proceeds at a faster rate to that of the dehydration of the C5-carbohydrates into furfural, therefore making the latter the rate determining process and the focus of mechanistic insights [64]. By analyzing isotope-labeled experimental evidence and activation energies, a comprehensive reaction mechanism that involves only acyclic intermediates was proposed, excluding the closedring mechanism proposed by Antal et al. [65], due to a particularly low activation energy for the $0-5$ protonation and subsequent ring opening of the cyclic intermediate 2,5-anhydroxylose.

In particular, it is suggested that xylose undergoes (i) aldoseketose isomerization via 1,2-hydride shift to xylulose that eventually leads to furfural via the 1,2-enediol or side-reactions and humins, predominant at $\mathrm{pH}<1$ with higher conversion rates, (ii) enolization to 1,2-enediol followed by two consecutive dehydration reactions to furfural via the 2,3-( $\alpha, \beta)$-unsaturated aldehyde, catalyzed by halides anions and favored at $\mathrm{pH} \mathrm{ca}$. 3, (iii) $\beta$ elimination that follows the pattern via $2,3-(\alpha, \beta)$-unsaturated aldehyde (vide supra), and (iv) equilibrium with D-xylopyranose that leads to unspecified side products, as shown in Scheme 2. The proposed reaction pathway validated the open ring mechanisms suggested by Ahmad [66] and Feather [67] by combining them both.

Further experimental evidence is required in elucidating this complex mechanism. Nonetheless, it can be drawn out that the key steps that require catalysis in order to derive higher furfural yields are isomerization/enolization and dehydration reactions which are catalyzed under basic and acid media, respectively.

Current industrial production of furfural still relies on homogeneous acid catalysts. The first furfural production was reported by Quaker Oats, based on oat hulls conversion in the presence of sulfuric acid at $153^{\circ} \mathrm{C}$ for $5 \mathrm{~h}$. Heating of the process was achieved by continuous steam injection, which also stripped furfural from the reaction environment, with yields of $c a$. 50\% [64]. The biggest furfural exporter of modern times (accounting for $70 \%$ of furfural production), China, has based their own process on the 1921 Quaker Oats, employing sulfuric acid (3-4 wt\%) and steam stripping in the conversion of corncobs, with a similar furfural yield of the former process. The moderate yields of furfural are mainly due to the formation of solid humins (vide infra), deriving from the occurrence of undesired polymerization reactions. As mentioned above, furfural is produced as co-chemical in the levulinic acid Biofine process. A furfural yield of $70 \%$ can be achieved from cellobiose at a $20 \mathrm{~min}$ residence time, operating at $210-220^{\circ} \mathrm{C}$ with $3 \%$ of sulfuric acid under 25 bar pressure of steam [68].

Alternatively, recent scientific progress provided significant advances in furfural production. Several mineral acids were also investigated in the production of furfural from a variety of biomass sources. Rice husks have proven to be ineffective in the production of furfural (9\% yield [69]), while olive stones conversion yielded $65 \%$ furfural at $230^{\circ} \mathrm{C}$ with sulfuric acid [63]. A screening of various mineral acids (i.e. $\mathrm{HCl}, \mathrm{H}_{2} \mathrm{SO}_{4}, \mathrm{HNO}_{3}$, and $\mathrm{H}_{3} \mathrm{PO}_{4}$ ) along with organic Trifluoroacetic acid (TFA) catalysts in the production of furfural 
Table 2

Summary of literature reported MeL yields from various substrates using heterogeneous catalysts.

\begin{tabular}{|c|c|c|c|c|c|}
\hline Catalyst & Substrate & $T\left({ }^{\circ} \mathrm{C}\right)$ & $t(\min )$ & Yield (\%) & Ref. \\
\hline Me-PST & Levulinic acid & 25 & 120 & 88 & [37] \\
\hline SBA-15- $\left(\mathrm{CH}_{2}\right)_{3}-\mathrm{SO}_{3} \mathrm{H}$ & Levulinic acid & 117 & 120 & 95 & [36] \\
\hline $\mathrm{H}_{4} \mathrm{SiW}_{12} \mathrm{O}_{40}-\mathrm{SiO}_{2}$ & Levulinic acid & 65 & 360 & 73 & [38] \\
\hline $\mathrm{H}_{3} \mathrm{PW}_{12} \mathrm{O}_{40} / \mathrm{ZrO}_{2}-\mathrm{Si}(\mathrm{Ph}) \mathrm{Si}$ & Levulinic acid & 65 & 180 & 99 & [40] \\
\hline H-USY & Glucose & 160 & 1800 & 49 & [43] \\
\hline H-USY & Cellulose & 160 & 1800 & 13 & [43] \\
\hline H-USY & Maltose & 160 & 1800 & 51 & [43] \\
\hline H-USY & Cellobiose & 160 & 1800 & 53 & [43] \\
\hline $\mathrm{SO}^{2-}{ }_{4 /} \mathrm{TiO}_{2}$ & Cellulose & 200 & 120 & 10 & [22] \\
\hline $\mathrm{SO}^{2-}{ }_{4 /} \mathrm{TiO}_{2}$ & Glucose & 200 & 120 & 33 & [22] \\
\hline $\mathrm{SO}^{2-}{ }_{4 /} \mathrm{TiO}_{2}$ & Sucrose & 200 & 120 & 43 & {$[22]$} \\
\hline $\mathrm{SO}^{2-}{ }_{4 /} \mathrm{TiO}_{2}$ & Fructose & 200 & 120 & 59 & {$[22]$} \\
\hline ZrY6 $(0.5)$ & Glucose & 180 & 3 & 68 & [44] \\
\hline ZrY6 (0.5) & Mannose & 180 & 3 & 70 & [44] \\
\hline ZrY6 (0.5) & Galactose & 180 & 3 & 73 & [44] \\
\hline ZrY6 (0.5) & Sucrose & 180 & 3 & 78 & [44] \\
\hline ZrY6 (0.5) & Cellobiose & 180 & 3 & 46 & [44] \\
\hline ZrY6 (0.5) & Starch & 180 & 3 & 53 & [44] \\
\hline ZrY6 (0.5) & Cellulose & 180 & 3 & 27 & [44] \\
\hline TZ50 & Fructose & 200 & 60 & 71 & [45] \\
\hline TZ50 & Sucrose & 200 & 60 & 54 & [45] \\
\hline TZ50 & Glucose & 200 & 60 & 23 & [45] \\
\hline Sulfonated biochar & Cellulose & 200 & 75 & 30 & [46] \\
\hline $\mathrm{PW}_{12} / \mathrm{Nb}_{2} \mathrm{O}_{5}-\mathrm{Si}(\mathrm{Ph}) \mathrm{Si}$ & Levulinic acid & 65 & 180 & 90 & [50] \\
\hline$[\mathrm{BMIM}-\mathrm{SH}]\left[\mathrm{H}_{2} \mathrm{SO}_{4}\right]$ & Furfuryl alcohol & 130 & 120 & 94 & [51] \\
\hline
\end{tabular}

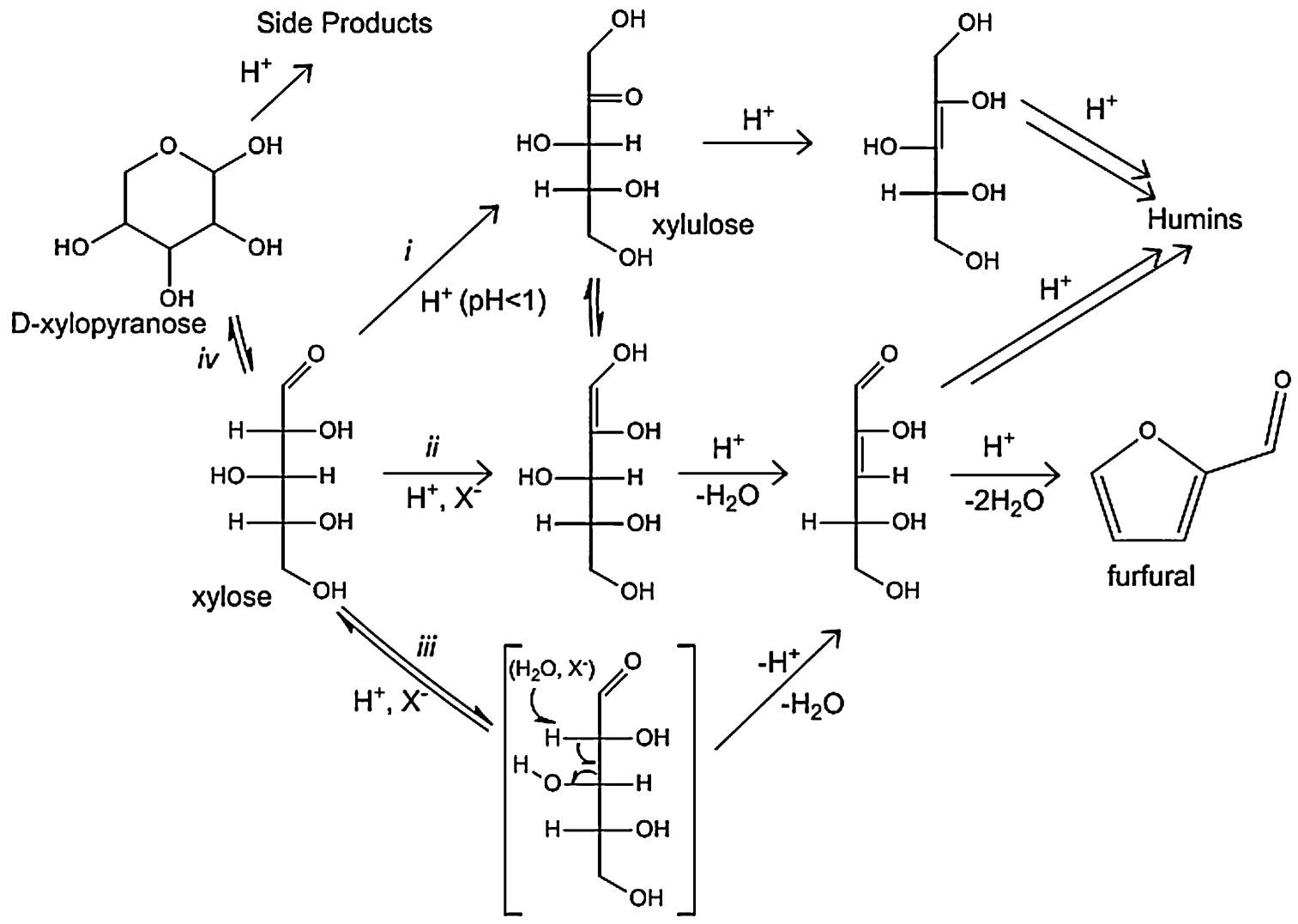

Scheme 2. Furfural formation mechanism proposed by Danon et al. adapted from Ref. [59].

from loblolly pine was conducted by Marzialetti et al. [70], finding reasonable furfural yields (and HMF and hexoses as by-products) at $200{ }^{\circ} \mathrm{C}$ for the TFA and sulfuric acid systems (57 and 34\%, respectively). Barbosa et al. [71] also screened mineral acids $\mathrm{HCl}, \mathrm{H}_{2} \mathrm{SO}_{4}$, and $\mathrm{H}_{3} \mathrm{PO}_{4}$ in the homogeneous liquid phase dehydration different biomasses, and found the best activity was given by chloridric acid, which yielded 30, 26, and 14\% furfural from corn stalk, sugar- cane bagasse, and eucalyptus wood, respectively. Phosphoric acid was found to be fairly active in the conversion of sorghum straw with furfural yield of 38\% [72], while maleic acid yielded 55\% furfural from switchgrass liquor [73]. Heteropolyacids were also employed in the dehydration of xylose. For instance, Dias et al. [74] reported furfural yields of 58-67\% at $140{ }^{\circ} \mathrm{C}$ employing $\mathrm{H}_{3} \mathrm{PW}_{12} \mathrm{O}_{40}$ (PW), and $\mathrm{H}_{4} \mathrm{SiW}_{12} \mathrm{O}_{40}(\mathrm{SiW})$ after $4 \mathrm{~h}$, while $\mathrm{H}_{3} \mathrm{PMo}_{12} \mathrm{O}_{40}$ showed 
Table 3

Overall view of homogeneous catalysts employed in furfural production.

\begin{tabular}{|c|c|c|c|c|c|}
\hline Catalyst & Substrate & $T\left({ }^{\circ} \mathrm{C}\right)$ & $t(\min )$ & Yield (\%) & Ref. \\
\hline $\mathrm{H}_{2} \mathrm{SO}_{4}$ & Oat hulls & 153 & 300 & 50 & [63] \\
\hline $\mathrm{H}_{2} \mathrm{SO}_{4}$ & Cellobiose & 210 & 20 & 70 & [68] \\
\hline $\mathrm{H}_{2} \mathrm{SO}_{4}$ & Rice husks & 230 & 288 & 9 & [69] \\
\hline $\mathrm{H}_{2} \mathrm{SO}_{4}$ & Olive stone & 230 & 2.5 & 65 & [63] \\
\hline $\mathrm{H}_{2} \mathrm{SO}_{4}$ & Loblolly pine & 200 & 60 & 34 & [69] \\
\hline TFA & Loblolly pine & 200 & 60 & 57 & [69] \\
\hline $\mathrm{HCl}$ & Eucalyptus wood & 170 & 180 & 14 & [71] \\
\hline $\mathrm{HCl}$ & Sugarcane bagasse & 170 & 180 & 26 & [71] \\
\hline $\mathrm{HCl}$ & Corn stalk & 170 & 180 & 30 & [71] \\
\hline $\mathrm{H}_{3} \mathrm{PO}_{4}$ & Sorghum straw & 134 & 300 & 38 & [72] \\
\hline Maleic acid & Switchgrass liquor & 200 & 15 & 55 & [73] \\
\hline $\mathrm{H}_{3} \mathrm{PW}_{12} \mathrm{O}_{40}$ & Xylose & 140 & 240 & 67 & [74] \\
\hline $\mathrm{H}_{4} \mathrm{SiW}_{12} \mathrm{O}_{40}$ & Xylose & 140 & 240 & 58 & [74] \\
\hline $\mathrm{HCl}+\mathrm{NaCl}$ & Xylose & 200 & 3.3 & 81 & [75] \\
\hline
\end{tabular}

the lowest activity. A combination of acid-base catalysts has also been employed, reaching 76\% furfural yield as reported by Choudhary et al. [75]. Addition of halide salts to mineral catalysts has also proved the increase of furfural production. In particular, Marcotullio et al. screened $\mathrm{NaCl}, \mathrm{KCl}, \mathrm{KBr}, \mathrm{CaCl}_{2}$, and $\mathrm{FeCl}_{3}$, finding sodium chloride as the most effective [76]. In fact, halide salts not only possess the ability of salting-out furfural in biphasic systems $[77,78]$, therefore reducing overall residence time and possible side-reactions, but also enhance furfural selectivities to up to $90 \%$ at $200^{\circ} \mathrm{C}$ as seen by Marcotullio et al. [76] in the co-presence of $\mathrm{HCl}$, and $\mathrm{NaCl}$. Higher selectivity is reported to be given by an acceleration in the 1,2-enediol formation by the weak base behavior of chlorine ions. Although the use of mineral acid catalysts simplifies operations, and fairly high yields of furfural can be obtained, these homogeneous acid systems present numerous drawbacks including corrosion, acidic waste disposal, and catalyst loss. Therefore, solid acid catalysis might seem a greener choice in the production of furfural. An overview of the homogeneous catalysts reported in this review is presented in Table 3.

\subsection{Heterogeneously catalyzed production of furfural}

As for heterogeneous catalysis is concerned, a distinctive reaction pathway has yet to be described as just few mechanistic investigations are being advanced in this matter. In the presence of Brønsted-acid catalysts, a cyclo-dehydration mechanism is most likely to occur where a pseudo-cycle undergoes ring-opening and subsequent ring closing to furfural, described by Zeitsch [64]. In particular, xylose undergoes as a sequence of two proton-catalyzed 1,2 -eliminations that open the pentose ring, followed by a 1,4 elimination that closes the ring yielding furfural. Instead, in the case of Brønsted acids combined with Lewis acid sites (either in homogeneous or heterogeneous phase), all experimental evidence suggest that the synergistic effect of the two types of acids promote xylose isomerization to xylulose, and overall increasing furfural yields by accelerating overall xylose conversion rate. For instance, Choudhary et al. [75] reported a $10 \%$ increase of furfural yields in water, and a $47 \%$ increase in a water/toluene medium (toluene acts as furfural-extracting solvent) when a Lewis acid (i.e. $\mathrm{CrCl}_{3}$ ) is added to a homogeneous Brønsted acid (i.e. $\mathrm{HCl}$ ), suggesting a mechanism via isomerization to xylulose (and the other isomer, lyxose) only in the presence of a Lewis acid catalyst but without proposing a full reaction mechanism.

Recently, Shirotori et al. [79] studied the xylose conversion in the presence of Brønsted acid Amberlyst-15 and acid-base catalyst $\mathrm{Cr} /$ hydrotalcites. The research group proposed a reaction mechanism based on ring opening and Lobry de Bruyn-Alberda van Ekenstein transformations (aldose-ketose). The suggested mechanism does not exclude a catalytic activity of dispersed $\mathrm{Cr}_{2} \mathrm{O}_{3}$ particles in the direct hydride shift for xylose-xylulose isomerization, however, a much lower furfural yield of solely $\mathrm{Cr}_{2} \mathrm{O}_{3}$ (4\%) compared to solely HT Brønsted base catalyst (19\%) suggest that the latter is indeed the main active site. With this in mind, a first xylopyranose- $\mathrm{Cr}_{2} \mathrm{O}_{3}$ coordination initiates the reaction by increasing the positive charge on the $\mathrm{C} 1$ oxygen atom and favors HT-catalyzed deprotonation to open-chain xylose. Subsequently, another deprotonation occurs at the $\mathrm{C} 2 \mathrm{H}$ of xylose by means of $\mathrm{HT}$, generating an 1,2-enediol which complexes with the $\mathrm{Cr}$-Lewis acid that undergoes proton shift from $\mathrm{C} 2$ to $\mathrm{C} 1$, generating xylulose. Ultimately, it is reported that xylulose will be dehydrated to furfural thanks to the catalytic activity of Brønsted acid Amberlyst15. However, these mechanisms do not take into consideration the numerous side reactions that limit furfural yields including polymerization or degradation reactions that lead to humins (vide infra) and decomposition products (e.g. formic acid, lactic acid, pyruvaldehyde [65]), respectively.

In conclusion, a defined scheme of this complex mechanism has yet to be elucidated, but a co-existence of Lewis and Brønsted acids may remarkably improve furfural yields.

The tunable acidities, excellent thermal and chemical stability and pore selectivity properties of zeolites make them attractive catalysts in xylose dehydration to furfural. Moreau et al. [80] first reported the use of microporous zeolites in the selective preparation of furfural, studying $\mathrm{H}-\mathrm{Y}$ Faujasite $(\mathrm{Si} / \mathrm{Al}=10$ and 15$), \mathrm{H}$-Mordenite $(\mathrm{Si} / \mathrm{Al}=11$ and 12$)$ in water/toluene and water/methylisobutylketone (1:3 by volume) in the conversion of xylose at $170^{\circ} \mathrm{C}$ for $30 \mathrm{~min}$. Furfural selectivity of $96 \%$ was achieved with $\mathrm{H}$-Mordenite $(\mathrm{Si} / \mathrm{Al}=11)$ in water/toluene medium ( $96 \%$ after $30 \mathrm{~min}$ of reaction), while in water/methyl isobutyl ketone furfural selectivity for $\mathrm{H}$-Mordenite $(\mathrm{Si} / \mathrm{Al}=12)$ was $51 \%$. The highest xylose conversion was observed for the catalyst with the lowest $\mathrm{Si} / \mathrm{Al}$ (HY Faujasite, $\mathrm{Si} / \mathrm{Al}=10$ ), due to the accessibility of xylose into the 3D structure of HY-Faujasite and pores of $c a$. $13 \AA$. However, large pore volumes also favor further rearrangements of furfural into degradation and/or polymerization compounds. Along these lines, Bruce et al. [81] investigated small pore zeolite catalysts (both synthesized and commercial) in the conversion of xylose in a $\gamma$-valerolactone/water system. Lessard et al. [82] tested higher temperatures $\left(260^{\circ} \mathrm{C}\right)$ for xylose conversion over a variety of zeolites, finding that phosphoric acid treatment on mordenite 13 catalysts could increased furfural yields to $98 \mathrm{~mol} \%$ with almost quantitative xylose conversion (99\%). O'Neill et al. [83] obtained 46\% furfural yield at $200^{\circ} \mathrm{C}$ over protonic $\mathrm{H}-\mathrm{ZSM}-5$ (pore size of $1.2 \mathrm{~nm}$ ) in water environment. Different zeolites were investigated by Kim et al. [84] in different reaction media (i.e. $\mathrm{H}_{2} \mathrm{O}, \mathrm{H}_{2} \mathrm{O}$ /toluene, and DMSO), reporting lower conversion and furfural yields in water medium, and a general decrease of catalytic activity in furfural production with increasing $\mathrm{SiO}_{2} / \mathrm{Al}_{2} \mathrm{O}_{3}$ ratios, which is closely correlated to acid sites accessibility.

This indicates that furfural yields critically depend on residence time in water media (therefore, validating biphasic systems), and on reagent/product diffusion limitations in porous systems. As an attempt to avoid this phenomenon, Lima et al. [85] attempted to achieve single crystalline sheets of layered aluminosilicates precursors through swelling and ultrasonication. The delaminated zeolites showed a remarkable increase in surface area and a slight decrease of the $\mathrm{Si} / \mathrm{Al}$ ratio, and yield to $47 \%$ furfural at $170^{\circ} \mathrm{C}$ in a water/toluene solution. The same research group, in a later paper[86], reported 58\% furfural selectivity of the medium-large pore size silicoaluminophosphates (SAPOs 5, 11, 40) with the highest Brønsted acid content and surface area. SAPOS are known to possess less but stronger acid-sites, thanks to the phosphorous substitution with Si. Overall, studies employing SAPO-5, -11, -40, and -44 reported furfural yields of $40-65 \%$ in biphasic systems [86,87]. Similarly, Valente et al. [85,87] prepared delaminated zeolites by 
swelling and ultrasonication from ferrierite, Nu-6(2), and MCM-22 (ITQ-2). Higher surface area and porosity of the delaminated compounds lead to higher furfural yields by favoring internal diffusion.

Mesoporous acid catalysts, such as SBA-15 and MCM-41 have been receiving increasing attention in biomass conversion. Xylose conversion to furfural was achieved with a $68 \%$ yield by Shi et al. [89] over $\mathrm{SBA}-15-\mathrm{SO}_{3} \mathrm{H}$ in water/toluene environment. MCM-41 showed low thermal stability of the acid sites and furfural yields lower than $40 \%$ in DMSO or water/butanol (48\% in water/butanol with the addition of $\mathrm{NaCl}$ [90]), while modified $\mathrm{MCM}-41-\mathrm{SO}_{3} \mathrm{H}$ showed increased activities in water/methyl isobutyl ketone and water/toluene, with furfural yields of $51 \%$ and $76 \%$, respectively $[90,91]$. For these catalytic systems, the higher activity was due to the nature of the MCM acid sites, and not its porous structure. In fact, as mentioned before, Lewis acid sites favor the isomerization of xylose to xylulose that possess overall faster reaction kinetics to furfural rather than the direct xylose-furfural pathways catalyzed by Brønsted acid sites. Increasing acid strength may increase reaction rates, but also further catalyze polymerization side-reactions $[61,75,86,92]$. An optimum Lewis/Brønsted acid sites ratio has been reported between 30 and 80\% [93]. Among other mesoporous acid catalysts investigated, high furfural yields of $82-86 \%$ were obtained with propylsulfonic-SBA [94] and arenesulfonic-SBA [95], respectively, thanks to their optimum BET surface area and pore size. Yields of $78 \%$ were reported for flurosulfonic modified $\mathrm{MgF}_{2}$ catalysts (71 wt\% HF) in water/toluene at $160{ }^{\circ} \mathrm{C}$ [95], and $\mathrm{Nb}_{2} \mathrm{O}_{5} /$ Cabosil in water at $175^{\circ} \mathrm{C}$ [96], with good Lewis/Brønsted acid sites ratio. Strong acid PTSA-POM catalyst also resulted into high furfural yields (ca. $80 \%$ ) at $170^{\circ} \mathrm{C}$ for $10 \mathrm{~min}$ in GVL/water [97]. Furfural yields reported in literature from xylose conversion are summarized in Table 4.

Heterogeneous conversion of whole biomass has been also attempted (Table 5). One-pot hydrolysis/dehydration of raw biomass (softwood hemicelluloses) to furfural has been carried out by Dhepe et al. [98] using HUSY, H-Beta, and H-mordenite, however only ca. $12 \%$ of furfural was recovered. Corn cob conversion with mixed metal oxide $\mathrm{ZrO}_{2}-\mathrm{TiO}_{2}$ at $300{ }^{\circ} \mathrm{C}$ yielded only $10 \%$ furfural [99]. A higher furfural yield of $c a .56 \%$ was instead achieved for bagasse conversion with HUSY in water $/ p$-xylene at $140^{\circ} \mathrm{C}$ after $300 \min [98,100]$.

Even though furfural traditionally is derived from C5carbohydrates, recently its production from hexoses has also been attempted using microporous ion exchanged H-Beta zeolites [101] (Table 5). A synergistic effect of textural properties (i.e. pore size comparable to furfural, and shorter pore pathways), Lewis/Brønsted acid sites ratio ( $c a .1 .3$, with the presence of mainly weak acid sites and small amounts of medium-strength) made SnBeta the most active catalyst, reaching $95 \%$ glucose conversion, $c a$. $68 \%$ furfural yield with a ca. $72 \%$ selectivity in $25 \mathrm{~min}$ at $170{ }^{\circ} \mathrm{C}$.

Comprehensively, a strict correlation of optimum surface areas, pore size, and acid type and strength exists in the xylose/biomass conversion in furfural. Limitations of this particular heterogeneous process are given by internal diffusion limitations, and optimized Lewis/Brønsted acid sites ratio. Comparable pore size to xylose and furfural molecular sizes (6.8 and $5.7 \AA$ A respectively) must be obtained, with ease accessibility given by a larger surface area; moreover, the right acid content and strength must be achieved, limited by the presence of too strong acid sites that catalyze secondary reactions [93].

In conclusion, environment-friendly heterogeneous catalysts are attractive possible alternatives to current homogeneous mineral acid catalysts employed in the industrial production of furfural.

Peleteiro et al. [58] wrote a recent review on the application of ionic liquids in furfural production. For sake of completeness, a very general overview is given herein. Their high boiling point, optimum dissolving capacity [103], chemical and thermal stability, recy- clability, and non-toxic nature (except for chloride-based) make ionic liquids an attractive green alternative to conventional solvents, however, their industrial application is still limited by their cost, and separability. Nonetheless, remarkable high yields were obtained in the dehydration of a variety of biomasses into furfural. The most notable examples will be given as follows. High activities were obtained when [BMIM]Cl (1-butyl-3-methylimidazolium chloride) was employed as solvent over a variety of substrates (lyxose, ribose, arabinose, xylose, pine wood), combined with a wide range of catalysts (Amberlyst- $15, \mathrm{H}_{3} \mathrm{PW}_{12} \mathrm{O}_{40}, \mathrm{PEG}-\mathrm{OSO}_{3} \mathrm{H}$, $\mathrm{CrCl}_{3}, \mathrm{AlCl}_{3}$ ) [101-106]. Remarkable yields of $\mathrm{ca}$. 94\% from xylan were reported when [BMIM] Cl was combined to $\mathrm{H}_{3} \mathrm{PW}_{12} \mathrm{O}_{40}$ [103] at $160^{\circ} \mathrm{C}$ for $10 \mathrm{~min}$. [BMIM] Cl and $\mathrm{CrCl}_{3}$ yielded $\mathrm{ca}$. $31 \%$ furfural from pine wood [105]. Overall, moderate-high furfural yields were reported for all systems (48-84\% from xylose, 75\% from lyxose, $90 \%$ from ribose, $72 \%$ from arabinose).

The possible release of halogens in the environment or consequences of its thermal decomposition, be it very slow, lead to the prevailing of scale-up studies for non-halide ionic liquids. [BMIM] $\mathrm{HSO}_{4}$ (1-butyl-3-methyl-imidazolium hydrogen sulphate) has yielded also to promising results when employed as both cosolvent and acid catalyst. For instance, Lima et al. [107] utilized [EMIM] $\mathrm{HSO}_{4}$ (1-ethyl-3-methylimidazolium hydrogen sulphate) combined with toluene, obtaining $84 \%$ furfural from xylose. Peleteiro et al. [108] reported yields of up to $82 \%$ when [BMIM] $\mathrm{HSO}_{4}$ was in the presence of dioxane, and of up to $80 \%$ with MIBK, in xylose dehydration at $140^{\circ} \mathrm{C}$. Attempts on whole biomass conversion were also attempted, yielding to 33\% furfural from Miscanthus giganteus at $120^{\circ} \mathrm{C}$ for $22 \mathrm{~h}$ [109], and yields of 36\% were reported from wheat straw dehydration, with up to $3 \%$ co-yield of HMF [110]. Ionic liquids, in conclusion, seem to have optimum employability for future furfural productions. However, the scarce technology knowledge of industrial production and unknown consequences of long-term use of ionic liquids, alongside their elevated cost and yet inefficient recovery and recycling, set some major drawbacks in the use of these systems. A number of furfural yields in ionic liquid systems are reported in Table 6 [54].

In general, furfural industrial production is feasible when yields exceed $50 \mathrm{wt} \%$, but many technological aspects can still be improved.

\section{Humins}

The limited yields of the products mentioned before (i.e. methyl levulinate, and furfural), alongside other products of dehydration reactions of biomass-derived carbohydrates (e.g. HMF, levulinic acid), are due to the formation of waste by-products. Among the latter, the most undesired by-products are given by the formation of so-called humins. These dark, tarry to solid, insoluble polymeric structures are favored by the aqueous acidic media of most lignocellulosic biomass homogeneous transformations, although most likely also present also when heterogeneous catalytic treatments are carried out in both water and/or organic solvents (Scheme 3).

For instance, 37-39\% yields of humins were reported in the mineral acid dehydration of aldose [111], while yields of even $50 \mathrm{wt} \%$ of humin by-products can derive from HMF production [112], and the typical furfural yields do not exceed $55 \%$ because of this sidereactions [113]. Although not yet unequivocally determined, the humin structure is known to depend on reaction time, temperature, and feedstock structure and its concentration [114-116]. Several kinetic studies on humin formation were performed. Values of $85-130 \mathrm{~kJ} \mathrm{~mol}^{-1}$ were reported for the activation energy for humin formation from HMF $[52,117,118]$; lower activation energies were found for the humins formed from furfural in the presence of either xylose or glucose, compared to furfural alone [119-121]. 
Table 4

Overall view of heterogeneous catalysts employed in furfural production from xylose.

\begin{tabular}{|c|c|c|c|c|c|c|}
\hline Catalyst & Substrate & Solvent & $T\left({ }^{\circ} \mathrm{C}\right)$ & $t(\min )$ & Yield (\%) & Ref. \\
\hline H-Mordenite & Xylose & Water/toluene & 170 & 50 & 33 & [78] \\
\hline H-Mordenite & Xylose & Water/methylisobutylketone & 170 & 50 & 20 & [78] \\
\hline HY-Faujasite & Xylose & Water/toluene & 170 & 50 & 42 & [78] \\
\hline HY-Faujasite & Xylose & Water/methylisobutylketone & 170 & 50 & 30 & [78] \\
\hline ZSM-5 & Xylose & Water $/ \gamma$-valerolactone & 190 & 15 & 70 & [81] \\
\hline Amberlyst-70 & Xylose & Water $/ \gamma$-valerolactone & 190 & 15 & 67 & [81] \\
\hline SAPO-34C & Xylose & Water $/ \gamma$-valerolactone & 190 & 360 & 40 & [81] \\
\hline SAPO-56 & Xylose & Water $/ \gamma$-valerolactone & 190 & 360 & 38 & [81] \\
\hline SAPO-34 & Xylose & Water $/ \gamma$-valerolactone & 190 & 360 & 31 & [81] \\
\hline H-Mordenite & Xylose & Water/toluene & 260 & 3 & 98 & [82] \\
\hline H-ZSM-5 & Xylose & Water & 200 & 30 & 46 & [84] \\
\hline H-ZSM-5 & Xylose & Water/toluene & 140 & 240 & 42 & [84] \\
\hline Del-Nu-6 & Xylose & Water/toluene & 170 & 240 & 47 & [85] \\
\hline SAPO-11 & Xylose & Water/toluene & 180 & 240 & 51 & [86] \\
\hline H-MCM-22 & Xylose & Water/toluene & 170 & 960 & 70 & [88] \\
\hline ITQ-2 & Xylose & Water/toluene & 170 & 960 & 66 & [88] \\
\hline SBA-15- $\mathrm{SO}_{3} \mathrm{H}$ & Xylose & Water/toluene & 160 & 240 & 68 & [89] \\
\hline $\mathrm{MCM}-41+\mathrm{NaCl}$ & Xylose & Water/1-butanol & 170 & 120 & 48 & [90] \\
\hline $\mathrm{MCM}-41-\mathrm{SO}_{3} \mathrm{H}$ & Xylose & DMSO & 140 & 1440 & 75 & [91] \\
\hline Propylsulfonic-SBA & Xylose & Water/toluene & 160 & 1200 & 82 & [94] \\
\hline Arenesulfonic-SBA & Xylose & Water/toluene & 160 & 1200 & 86 & [95] \\
\hline Fluorosulfonic $\mathrm{MgF}_{2}$ & Xylose & Water/toluene & 160 & 1200 & 78 & [96] \\
\hline $\mathrm{Nb}_{2} \mathrm{O}_{5} /$ Cabosil & Xylose & Water ( $\mathrm{N}_{2}$ stripping) & 175 & 180 & 78 & [97] \\
\hline PTSA-POM & Xylose & Water $/ \gamma$-valerolactone & 170 & 10 & 80 & [98] \\
\hline
\end{tabular}

Table 5

Overall view of heterogeneous catalysts employed in furfural production from substrates different from xylose.

\begin{tabular}{|c|c|c|c|c|c|c|}
\hline Catalyst & Substrate & Solvent & $T\left({ }^{\circ} \mathrm{C}\right)$ & $t(\min )$ & Yield (\%) & Ref. \\
\hline Amberlyst-70 & Switchgrass & Water $/ \gamma$-valerolactone & 190 & 30 & 60 & [81] \\
\hline SAPO-34C & Switchgrass & Water $/ \gamma$-valerolactone & 190 & 1440 & 30 & [81] \\
\hline SAPO-56 & Switchgrass & Water $/ \gamma$-valerolactone & 190 & 1440 & 29 & [81] \\
\hline HUSY & Softwood hemicelluloces & Water & 170 & 180 & 12 & [99] \\
\hline $\mathrm{ZrO}_{2}-\mathrm{TiO}_{2}$ & Corncob & Water & 300 & 5 & 10 & [100] \\
\hline HUSY & Bagasse & Water/p-xylene & 140 & 300 & 56 & {$[99,101]$} \\
\hline Sn-Beta & Glucose & $\gamma$-valerolactone & 170 & 25 & 68 & [102] \\
\hline
\end{tabular}

Table 6

Overall view of furfural production employing ionic liquids.

\begin{tabular}{|c|c|c|c|c|c|c|}
\hline Catalyst & Substrate & Solvent & $T\left({ }^{\circ} \mathrm{C}\right)$ & $t(\min )$ & Yield (\%) & Ref. \\
\hline $\mathrm{H}_{3} \mathrm{PW}_{12} \mathrm{O}_{40}$ & Xylan & [BMIM]Cl & 160 & 10 & 94 & [105] \\
\hline $\mathrm{CrCl}_{3}$ & Pine wood & {$[\mathrm{BMIM}] \mathrm{Cl}$} & $(400 W)$ & 3 & 34 & [107] \\
\hline$\left[\mathrm{EMIM} \mathrm{HSO}_{4}\right.$ & Xylose & [EMIM] $\mathrm{HSO}_{4} /$ toluene & 100 & 360 & 84 & [109] \\
\hline$[\mathrm{BMIM}] \mathrm{HSO}_{4}$ & Xylose & {$[\mathrm{BMIM}] \mathrm{HSO}_{4} /$ dioxane } & 140 & 360 & 82 & {$[110]$} \\
\hline$[\mathrm{BMIM}] \mathrm{HSO}_{4}$ & Xylose & {$[\mathrm{BMIM}] \mathrm{HSO}_{4} / \mathrm{MIBK}$} & 140 & 360 & 80 & [110] \\
\hline$[\mathrm{C} 4 \mathrm{C} 1 \mathrm{im}]\left[\mathrm{HSO}_{4}\right]_{80 \%}$ and $[\mathrm{C} 4 \mathrm{C} 1 \mathrm{im}]\left[\mathrm{MeSO}_{4}\right]_{80 \%}$ & Miscanthus giganteus & - & 120 & 1320 & 33 & [111] \\
\hline$[\mathrm{BMIM}] \mathrm{HSO}_{4}$ & Wheat straw & - & 160 & 157 & 36 & [112] \\
\hline
\end{tabular}

The kinetic study of glucose conversion to levulinic acid conducted by Girisuta et al. [122] reported higher activation energy for the formation of humins $\left(165 \mathrm{~kJ} \mathrm{~mol}^{-1}\right)$ than all of the other activation energies of glucose conversion. However, both Weingarten et al. [121], and Eifert and Liauw [123] obtained lower activation energies for humin formation compared to xylose dehydration to furfural, making humins thermodynamically favored. Moreover, Eifert and Liauw observed a linear correlation between the reaction rate of humin formation and temperature. Even nowadays, structural characterization is the main research focus, and still object of debate. One of the first studies on humin structure is given by F. A. H. Rice [111] in 1958, who performed IR analysis on homogeneously dehydrated aldoses, reporting the presence of hydroxyl, carbonyl and, possibly, carbon-carbon double bonds, as well as, highly similar spectra of the soluble and unsoluble humin fractions.

Sumerskii et al. [113] studied the multistep humin formation in acidic medium from monosaccharides. It was noted that the investigated pentose (i.e. arabinose) yielded more humins than the hexoses counterparts. This finding was suggested to be caused by the high reactivity of furfural, readily formed from pentose sugars, to undergo further condensation reactions to humin, while lower thermal stability would cause HMF to decompose in two stable acids (levulinic and formic acid). ${ }^{13} \mathrm{C}$ NMR analysis showed $35.1 \%$ of relative amount of carbons as carbon and hydrogen substituted $\mathrm{C}$ atoms in furan compounds; and $27.3 \%$ as oxygen-substituted $\mathrm{C}$ atoms in furans. Among the rest, in low percentages (2-4\%) each, carboxyl and esters, methoxy, $-\mathrm{CH}_{2} \mathrm{O}$ - fragments, and acetal carbon atoms were found. The same group, proposes also two reaction pathways for humin formation in pentoses and hexoses. For xylose dehydration, furfural polycondensate to humins via electrophilic substitution, forming $\mathrm{C}-\mathrm{C}$ bonds between furan rings. As hexoses concern, humin formation from HMF proceeds via aromatic electrophilic substitution, leading to ether or acetal bonds between rings.

Recently, pyrolytic humins were found to possess mainly carbonyl functional groups [124]. Horvat [125] first proposed the formation of highly reactive 2,5-dioxo-6-hydroxyhexanal (DHH), crucial molecule regarding humin formation, although DHH has 


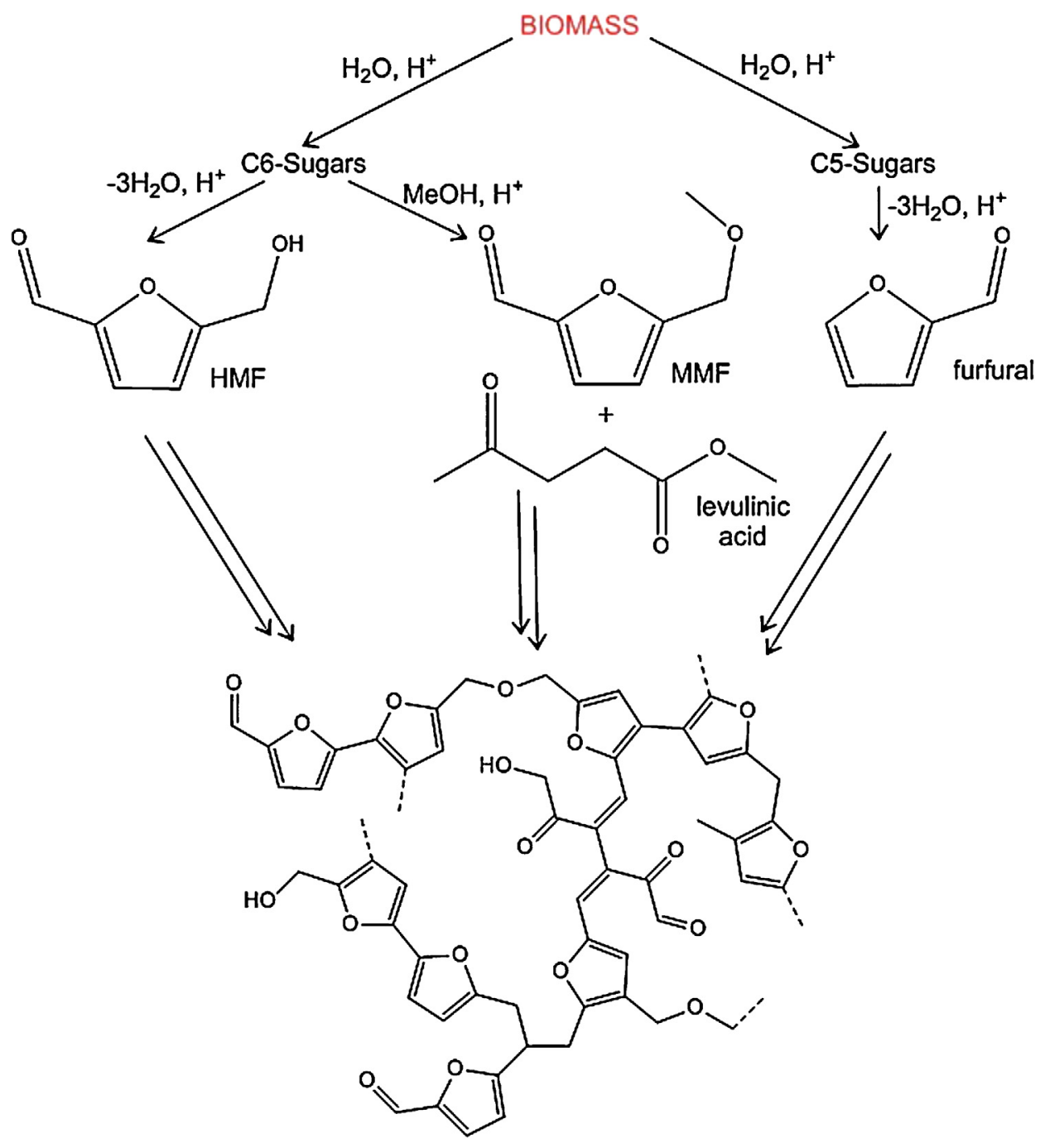

Scheme 3. Pathways formation of humin by-products.<smiles>CCCC=CC1=CCC(O)(CO)O1</smiles>

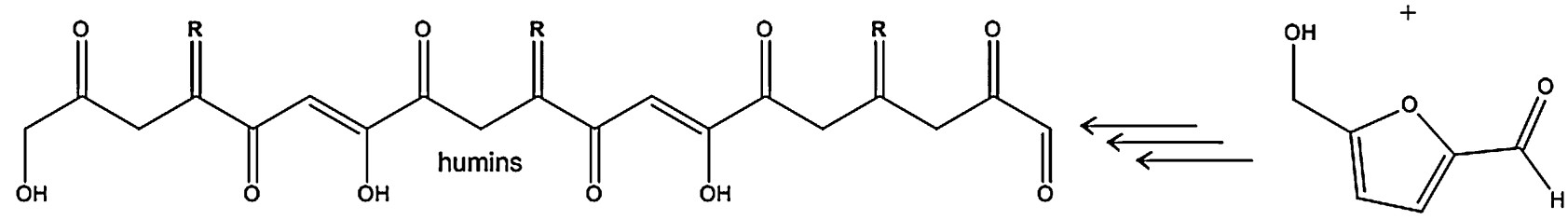<smiles>[R]Cc1cc(CO)oc1C</smiles>

Scheme 4. Humins formation mechanism as proposed by Lund et al., adapted from Ref. [126]. 
Table 7

Humins transformations reported in literature.

\begin{tabular}{|c|c|c|c|c|c|c|}
\hline Process & Catalyst & Conversion (\%) & $T\left({ }^{\circ} \mathrm{C}\right)$ & $t(\min )$ & Yield (\%) & Ref. \\
\hline Gasification & $\mathrm{Na}_{2} \mathrm{CO}_{3}$ & 100 & 750 & 30 & $81\left(\mathrm{H}_{2}\right)$ or 75 (syngas) & [114] \\
\hline Fast pyrolysis & - & - & 500 & $12 \mathrm{~s}$ & 30 (volatile) & [143] \\
\hline Hydrotreatment & $\mathrm{Ru} / \mathrm{C}$ & 69 & 400 & 360 & 65 (phenolics) & [144] \\
\hline Hydrotreatment & $\mathrm{Ru} / \mathrm{Al}_{2} \mathrm{O}_{3}$ & 59 & 400 & 360 & 70 (phenolics) & [144] \\
\hline
\end{tabular}

yet to be identified spectroscopically. This hypothesis was further accredited by Lund et al. $[118,126]$ in the humin formation from HMF. IR spectra showed the presence of an extensive conjugated network, and furan rings with aldehyde or ketone functional groups were supposed. The proposed mechanism involves DHH as key intermediate, formed by 2,3-addition of water to HMF. In particular, the highly reactive intermediate undergoes aldol condensations with the carbonyl group of HMF, yielding to humins (Scheme 4 ). However, the mechanism has not yet been unequivocally established.

Self-condensation of HMF or furfural has been postulated [127]; however, this possibility has been discarded by others [128]. Molecules such as HMF and furfural cannot undergo condensation reactions due to the absence of an $\alpha \mathrm{H}$-atom, pushing forward the theory that humins are formed via cross-polymerization reactions between HMF and either sugars or reactive HMF-derivatives [52]. Dee et al. [129] reported up to $30 \%$ humin yield in the hydrolysis of cellulose to glucose in ionic liquids and sulfuric acid. The research group observed an increase of humin yields with increasing HMF concentration, confirming the important role this molecule plays in humins formation. It was postulated that humins are formed via polymerization reactions of HMF with glucose, initiated by protonation of HMF aldehyde group followed by condensation with a sugar molecule. Similar findings were reported by Herzfeld et al. [130], who suggested that furan units act to cross-link sugar molecules. Akien et al. [131] investigated the dehydration of fructose to HMF with in situ NMR and ${ }^{13} \mathrm{C}$ labeling studies, intermediates that are believed to polymerize to humins. In particular, it was proposed that the furanose-type intermediate lead to HMF while pyranose forms lead to humins.

The formation and morphology of humins as a function of feedstock and operating conditions was recently studied [116]. It was found that humin formation is strongly influenced by reaction temperatures and acid concentrations but little effect was given to sugar concentrations. A dependence on the feedstock type was nonetheless observed, with higher humin formation from fructose due to the fast formation of HMF. Condensation reactions were attributed to nucleophilic attacks resulting in linkages at the $\alpha$ position of HMF, or substitution at the $\beta$ position.

Combination of elemental analysis, IR, ${ }^{13} \mathrm{C}$ ssNMR, and pyrolysis-GC-MS, lead to speculate a furanic structure formed via dehydration, with alcohol, acid, ketone and aldehyde groups. It was also noted that xylose-derived humins presented a more conjugated structure due to the reactivity of the free 5-position of furfural, as it is well-known in the formation of resins [132]. 1D and $2 \mathrm{D}$ ssNMR were performed by the same research group on ${ }^{13} \mathrm{C}$ labeled humins, in a later publication [133]. This study revealed that in the acidic dehydration of glucose, the major linkages in humins include $C_{\alpha}-C_{\text {aliphatic }}$ and $C_{\alpha}-C_{\alpha}$ bonds, while $C_{\beta}$ linkages were minor. Moreover, reactive solubilization via alkaline treatment on the humins formed a more aromatic structure, at the expense of the furan rings.

Tsilomelekis et al. [117] validates the proposed nucleophilic attack of a HMF carbonyl group to the $\alpha$ or $\beta$ position of the furanic ring, and ATR-FTIR indicated that humin formation involves a multitude of parallel reactions to the aldol condensation. Recent work by Wang et al. [134] reported FTIR and ${ }^{13} \mathrm{C}$ NMR analysis on glucose- and xylose-derived humins, finding ca. 50\% of carbon in furfural rings, and an abundance of oxygenated functional group. Xylose-derived humins, however, contained higher aliphatic content. Analysis of the volatiles from the pyrolysis of the two different humins showed similar compositions, with furans and phenols as the main products. Aromatic products and carbonization were favored by the high pyrolysis temperatures.

In conclusion, humin formation mechanism is largely unknown, alongside the various feedstocks intermediates. Nonetheless, some attempts in upgrading this humin waste have been attempted. Traditionally, the minimization of humic substances is usually preferred $[135,136]$. For example, less humins were observed with toluene extraction in the ethanolysis of carbohydrates [135], and addition of co-solvents such as GVL and methyl-THF $[137,138]$. However, different approaches have been taken into consideration for upgrading this unavoidable waste. Steam reforming of humins was reported by Hoang et al. [112] at $750^{\circ} \mathrm{C}$ over a variety of alkali- and alkaline-earth based catalysts, $\mathrm{Na}_{2} \mathrm{CO}_{3}$ was found to be the most effective giving a complete conversion of humins with a $75 \%$ selectivity to syngas $\left(81 \% \mathrm{H}_{2}\right.$ yield). Byun et al. [139] proposed the integration of a heat exchanger that utilizes lignin and humins as combustible in the production of butene oligomers from cellulose. Humins have also been integrated in polyfurfuryl alcohol (PFA) polymeric structure, creating a new composite with lower brittleness than the pure PFA sample [140]. These various material applications might seem direct and simple for the undesired substances. Humins offer the potential also to liberate highly added-value chemicals. Rasrendra et al. [141] reported, in fact, that liquefaction of humins by fast pyrolysis yielded low molecular furanics such as furfural and 2,5-dimethylfuran, which show a potential of obtaining important platform chemicals from the humic waste. Wang et al. [142] reported the hydrocracking and hydrodeoxygenation of low molecular weight humins, with a mixture of formic acid and isopropanol over rutheniumbased catalysts at $400-500^{\circ} \mathrm{C}$. The main products obtained were naphthalenes, alkylphenolics, and cyclicoalkanes. Other products included alkanes, aromatics, and polyaromatic hydrocarbons. Remarkable humin conversions of $69 \%$ were obtained on $\mathrm{Ru} / \mathrm{C}$ with formic acid, while $\mathrm{Ru} / \mathrm{Al}_{2} \mathrm{O}_{3}$ gave only $59 \%$ humin conversion. These results pointed out the potential of humins as new feedstocks rather than traditional waste (Table 7).

\section{Conclusions and future prospects}

This manuscript was aimed to provide a general overview on the various possibilities to valorize three key biomass-derived side products from hemicellulosic fraction processing. MeL, as well as in general levulinate esters, have per-se remarkable properties with potential applications in the fragrances and flavoring industries and additional possibilities to be converted into a number of useful derivatives (e.g. gamma-valerolactone) and can be simply produced from a number of biomass feedstocks under both homogeneous and heterogeneous catalysis. Interestingly, fine-tuning Lewis/Brønsted acid sites ratios, the presence of medium strength acid sites and a regular pore size distribution to avoid diffusional 
issues in MeL production (only for solid acid catalysts) seem to be critical to develop in order to maximize MeL yields for its subsequent conversion to valuable chemicals and fuels.

Furfural is one of the most promising furanic compounds that can be obtained from C5 sugars via dehydration. Furfural production can be industrially feasible when yields exceed $50 \mathrm{wt} \%$ for which both homogeneous and heterogeneous systems have been reported starting from a number of biomass-derived feedstocks (also different from xylose). The key in maximizing furfural yields from C5 sugars lies in the design of catalytic systems featuring optimum acidities (strength $v$ s type of acid sites), surface areas, pore sizes, etc. to minimize humins and side products formation - generally produced under mineral acid catalyzed dehydration or in the presence of too strong acid sites - in the dehydration step.

Last, but not least, humins as generated intractable furanic polymers originate from dehydration reactions of biomass-derived carbohydrates which have a remarkable potential for their conversion into valuable chemicals and fuel precursors (e.g. furanics and aromatics) as well as materials. Their unknown and poorly characterized structures to date make such catalytic processing a significant challenge which however can provide alternative research avenues to companies currently producing humins as waste product from sugar-related chemistries.

The selected examples illustrate the potential in the production of biomass-derived side products in view of their potential valorization to chemicals, materials and fuels, with substrates including humins that will play a major role in future biorefineries to provide additional revenues to companies working on sugars processing.

\section{References}

[1] L. Wu, T. Moteki, A.A. Gokhale, D.W. Flaherty, F.D. Toste, Production of fuels and chemicals from biomass: condensation reactions and beyond, Chemistry 1 (2016) 32-58, http://dx.doi.org/10.1016/j.chempr.2016.05.002.

[2] M.J. Climent, A. Corma, S. Iborra, Conversion of biomass platform molecules into fuel additives and liquid hydrocarbon fuels, Green Chem. 16 (2014) 516, http://dx.doi.org/10.1039/c3gc41492b.

[3] S. De, A.M. Balu, J.C. van der Waal, R. Luque, Biomass-derived porous carbon materials: synthesis and catalytic applications, ChemCatChem 7 (2015) 1608-1629, http://dx.doi.org/10.1002/cctc.201500081.

[4] F.D. Pileidis, M.-M. Titirici, Levulinic acid biorefineries: new challenges for efficient utilization of biomass, ChemSusChem 9 (2016) 562-582, http://dx. doi.org/10.1002/cssc.201501405.

[5] M.-F. Li, S. Yang, R.-C. Sun, Recent advances in alcohol and organic acid fractionation of lignocellulosic biomass, Bioresour. Technol. 200 (2016) 971-980, http://dx.doi.org/10.1016/j.biortech.2015.10.004.

[6] K. Yan, Y. Yang, J. Chai, Y. Lu, Catalytic reactions of gamma-valerolactone: a platform to fuels and value-added chemicals, Appl. Catal. B: Environ. 179 (2015) 292-304, http://dx.doi.org/10.1016/j.apcatb.2015.04.030.

[7] D.E. Resasco, S. Sitthisa, J. Faria, T. Prasomsri, M.P. Ruiz, Furfurals as chemical platform for biofuels production, Heterogen. Catal. Biomass Chem. Fuels. 661 (2011) 1-33.

[8] T.A. Werpy, J.E. Holladay, J.F. White, Top Value Added Chemicals from Biomass: I. Results of Screening for Potential Candidates from Sugars and Synthesis Gas, US Department of Energy, 2004

$\langle$ http://www.eere.energy.gov/biomass/pdfs/35523.pdf $\rangle$ (accessed October 27, 2016).

[9] J.J. Bozell, G.R. Petersen, Technology development for the production of biobased products from biorefinery carbohydrates-the US Department of Energy's “Top 10” revisited, Green. Chem. 12 (2010) 539-554, http://dx.doi. org/10.1039/B922014C.

[10] M. Rose, R. Palkovits, Cellulose-based sustainable polymers: state of the art and future trends, Macromol. Rapid Commun. 32 (2011) 1299-1311, doi:10.1002/marc.201100230

[11] Avantium, (n.d.). 〈http://www.avantium.com〉 (accessed October 27, 2016)

[12] D.J. Hayes, An examination of biorefining processes, catalysts and challenges, Catal. Today 145 (2009) 138-151, http://dx.doi.org/10.1016/j. cattod.2008.04.017.

[13] C. Capelli. A preservative composition and its use, a method of preparing it and formulations containing it, EP2065025, 2009.

[14] L. Clarke, A. Felix-Moore, J.J.J. Louis, J. Smith. Liquid fuel compositions, WO2010000761 A1, 2010.

[15] R. Le Van Mao, Q. Zhao, G. Dima, D. Petraccone, New process for the acid-catalyzed conversion of cellulosic biomass (AC3B) into alkyl levulinates and other esters using a unique one-pot system of reaction and product extraction, Catal. Lett. 141 (2011) 271-276, http://dx.doi.org/10.1007/ s10562-010-0493-y.

[16] E.S. Olson, M.R. Kjelden, A.J. Schlag, R.K. Sharma, Levulinate esters from biomass wastes, ACS Symp. Ser. (2001) 51-63, http://dx.doi.org/10.1021/bk2001-0784.ch005.

[17] C. Sasikala, C.V. Ramana, P.R. Rao, 5-Aminolevulinic acid: a potential herbicide/insecticide from microorganisms, Biotechnol. Prog. 10 (1994) 451-459, http://dx.doi.org/10.1021/bp00029a001.

[18] S. Selifonov, Glycerol levulinate ketals and their use, US8053468 B2, 2011.

[19] P.M. Ayoub, Process for the reactive extraction of levulinic acid, WO2005070867 A1, 2005.

[20] W.E. Lawson, P.L. Salzberg, Levulinic acid ester, US2008720 A, 1935.

[21] E.I. Gürbüz, D.M. Alonso, J.Q. Bond, J.A. Dumesic, Reactive extraction of levulinate esters and conversion to $\gamma$-valerolactone for production of liquid fuels, ChemSusChem 4 (2011) 357-361, http://dx.doi.org/10.1002/cssc. 201000396.

[22] L. Peng, L. Lin, H. Li, Q. Yang, Conversion of carbohydrates biomass into levulinate esters using heterogeneous catalysts, Appl. Energy 88 (2011) 4590-4596, http://dx.doi.org/10.1016/j.apenergy.2011.05.049.

[23] P.M. Ayoub, J.-P. Lange, Process for converting levulinic acid into pentanoic acid, WO2008142127 A1, 2008

[24] X. Hu, C.-Z. Li, Levulinic esters from the acid-catalysed reactions of sugars and alcohols as part of a bio-refinery, Green Chem. 13 (2011) 1676, http:// dx.doi.org/10.1039/c1gc15272f.

[25] J. Xu, X. Xie, J. Wang, J. Jiang, Directional liquefaction coupling fractionation of lignocellulosic biomass for platform chemicals, Green Chem. 18 (2016) 3124-3138, http://dx.doi.org/10.1039/C5GC03070F.

[26] P.A. Russo, M.M. Antunes, P. Neves, P.V. Wiper, E. Fazio, F. Neri, F. Barreca, L. Mafra, M. Pillinger, N. Pinna, A.A. Valente, Mesoporous carbon-silica solid acid catalysts for producing useful bio-products within the sugar-platform of biorefineries, Green Chem. 16 (2014) 4292-4305, http://dx.doi.org/10. 1039/c4gc01037j.

[27] Z. Chen, Y. Feng, T. Tong, A. Zeng, Effects of acid-modified HBEA zeolites on thiophene acylation and the origin of deactivation of zeolites, Appl. Catal. A: Gen. 482 (2014) 92-98, http://dx.doi.org/10.1016/j.apcata.2014.05.028.

[28] L. Zhou, T. Lu, J. Xu, M. Chen, C. Zhang, C. Chen, X. Yang, J. Xu, Synthesis of hierarchical MeAPO-5 molecular sieves-catalysts for the oxidation of hydrocarbons with efficient mass transport, Microporous Mesoporous Mater. 161 (2012) 76-83, http://dx.doi.org/10.1016/j.micromeso.2012.04. 058.

[29] B. Girisuta, L.P.B.M. Janssen, H.J. Heeres, A kinetic study on the decomposition of 5-hydroxymethylfurfural into levulinic acid, Green Chem. 8 (2006) 701, http://dx.doi.org/10.1039/b518176c

[30] C.-H. Zhou, X. Xia, C.-X. Lin, D.-S. Tong, J. Beltramini, Catalytic conversion of lignocellulosic biomass to fine chemicals and fuels, Chem. Soc. Rev. 40 (2011) 5588, http://dx.doi.org/10.1039/c1cs15124j.

[31] M. Moliner, Y. Román-Leshkov, M.E. Davis, Tin-containing zeolites are highly active catalysts for the isomerization of glucose in water, Proc. Natl. Acad. Sci. U.S.A. 107 (2010) 6164-6168, http://dx.doi.org/10.1073/pnas. 1002358107.

[32] K. Garves, Preparation of Alkoxymethylfurfurals and Alkyl Levulinates from Cellulose or Lignocelluloses or Starches and Alcohols, DE3621517, 1988

[33] K. Garves, Acid catalyzed degradation of cellulose in alcohols, J. Wood Chem. Technol. 8 (1988) 121-134, http://dx.doi.org/10.1080/02773818808070674.

[34] X. Wu, J. Fu, X. Lu, One-pot preparation of methyl levulinate from catalytic alcoholysis of cellulose in near-critical methanol, Carbohydr. Res. 358 (2012) 37-39, http://dx.doi.org/10.1016/j.carres.2012.07.002.

[35] L. Peng, H. Li, L. Lin, K. Chen, Effect of metal salts existence during the acid-catalyzed conversion of glucose in methanol medium, Catal. Comm. 59 (2015), http://dx.doi.org/10.1016/j.catcom.2014.09.028.

[36] L. Zhou, H. Zou, J. Nan, L. Wu, X. Yang, Y. Su, T. Lu, J. Xu, Conversion of carbohydrate biomass to methyl levulinate with $\mathrm{Al}_{2}\left(\mathrm{SO}_{4}\right)_{3}$ as a simple, cheap and efficient catalyst, Catal. Comm. 2 (2014), http://dx.doi.org/10 1016/j.catcom.2014. 02.021.

[37] B. Erb, J.-P. Kucma, S. Mourey, F. Struber, Polymer-supported triazenes as smart reagents for the alkylation of carboxylic acids, Chem.-Eur. J. 9 (2003) 2582-2588, http://dx.doi.org/10.1002/chem.200204739.

[38] J.A. Melero, G. Morales, J. Iglesias, M. Paniagua, B. Hernández, S. Penedo, Efficient conversion of levulinic acid into alkyl levulinates catalyzed by sulfonic mesostructured silicas, Appl. Catal. A: Gen. 466 (2013) 116-122, http://dx.doi.org/10.1016/j.apcata.2013.06.035.

[39] K. Yan, G. Wu, J. Wen, A. Chen, One-step synthesis of mesoporous $\mathrm{H}_{4} \mathrm{SiW}_{12} \mathrm{O}_{40}-\mathrm{SiO}_{2}$ catalysts for the production of methyl and ethyl levulinate biodiesel, Catal. Commun. 34 (2013) 58-63, http://dx.doi.org/10. 1016/j.catcom.2013.01.010.

[40] F. Su, L. Ma, D. Song, X. Zhang, Y. Guo, Design of a highly ordered mesoporous $\mathrm{H} 3 \mathrm{PW} 12 \mathrm{O} 40 / \mathrm{ZrO} 2-\mathrm{Si}(\mathrm{Ph}) \mathrm{Si}$ hybrid catalyst for methyl levulinate synthesis, Green Chem. 15 (2013) 885-890, http://dx.doi.org/10.1039/C3GC36912A.

[41] D.R. Fernandes, A.S. Rocha, E.F. Mai, C.J.A. Mota, V. Teixeira da Silva, Levulinic acid esterification with ethanol to ethyl levulinate production over solid acid catalysts, Appl. Catal. A: Gen. 425 (2012) 199-204, http://dx.doi. org/10.1016/j.apcata.2012.03.020

[42] K. Tominaga, A. Mori, Y. Fukushima, S. Shimada, K. Sato, Mixed-acid systems for the catalytic synthesis of methyl levulinate from cellulose, Green Chem. 13 (2011) 810, http://dx.doi.org/10.1039/c0gc00715c. 
[43] S. Saravanamurugan, A. Riisager, Zeolite catalyzed transformation of carbohydrates to alkyl levulinates, ChemCatChem 5 (2013) 1754-1757, http://dx.doi.org/10.1002/cctc.201300006.

[44] H. Li, Z. Fang, J. Luo, S. Yang, Direct conversion of biomass components to the biofuel methyl levulinate catalyzed by acid-base bifunctional zirconia-zeolites, Appl. Catal. B: Environ. 200 (2017) 182-191, http://dx.doi. org/10.1016/j.apcatb.2016.07.007.

[45] E.C. Njagi, H.C. Genuino, C.-H. Kuo, S. Dharmarathna, A. Gudz, S.L. Suib, High-yield selective conversion of carbohydrates to methyl levulinate using mesoporous sulfated titania-based catalysts, Microporous Mesoporous Mater. 202 (2015) 68-72, http://dx.doi.org/10.1016/j.micromeso.2014.09. 044.

[46] S. Dora, T. Bhaskar, R. Singh, D.V. Naik, D.K. Adhikari, Effective catalytic conversion of cellulose into high yields of methyl glucosides over sulfonated carbon based catalyst, Bioresour. Technol. 120 (2012) 318-321, http://dx. doi.org/10.1016/j.biortech.2012.06.036.

[47] X. Xu, X. Zhang, W. Zou, H. Yue, G. Tian, S. Feng, Conversion of carbohydrates to methyl levulinate catalyzed by sulfated montmorillonite, Catal. Comm. 62 (2015), http://dx.doi.org/10.1016/j.catcom.2015.01.011.

[48] D. Ding, J. Xi, J. Wang, X. Liu, G. Lu, Y. Wang, Production of methyl levulinate from cellulose: selectivity and mechanism study, Green Chem. 17 (2015) 4037-4044, http://dx.doi.org/10.1039/C5GC00440C.

[49] R.H. Lock, K. Reynolds, Levulinic Acid Esters, GB735693, 1955.

[50] S. An, D. Song, Y. Sun, Y. Guo, Q. Shang, Design of highly ordered mesoporous $\mathrm{Nb}_{2} \mathrm{O}_{5}$-based hybrid catalysts bifunctionalized by the Keggin-type heteropoly acid and phenyl-bridged organosilica moieties for the synthesis of methyl levulinate, Microporous Mesoporous Mater. 226 (2016) 396-405 http://dx.doi.org/10.1016/j.micromeso.2016.02.019.

[51] A.M. Hengne, S.B. Kamble, C.V. Rode, Single pot conversion of furfuryl alcohol to levulinic esters and $\gamma$-valerolactone in the presence of sulfonic acid functionalized ILs and metal catalysts, Green Chem. 15 (2013) 2540, http://dx.doi.org/10.1039/c3gc41098f.

[52] R.-J. van Putten, J.C. van der Waal, E. de Jong, C.B. Rasrendra, H.J. Heeres, J.G de Vries, Hydroxymethylfurfural, a versatile platform chemical made from renewable resources, Chem. Rev. 113 (2013) 1499-1597, http://dx.doi.org/ $10.1021 / \mathrm{cr} 300182 \mathrm{k}$.

[53] IFC, supplier in furfural., (n.d.). 〈http://www.furan.com/furfural.html〉 (accessed October 10, 2016).

[54] C.M. Cai, T. Zhang, R. Kumar, C.E. Wyman, Integrated furfural production as a renewable fuel and chemical platform from lignocellulosic biomass, J. Chem. Technol. Biotechnol. 89 (2014) 2-10, http://dx.doi.org/10.1002/jctb.4168.

[55] A.E. Eseyin, P.H. Steele, An overview of the applications of furfural and its derivatives, Int. J. Adv. Chem. 3 (2015) 42-47, http://dx.doi.org/10.14419/ ijac.v3i2.5048.

[56] K. Yan, C. Jarvis, J. Gu, Y. Yan, K. Yan, C. Jarvis, J. Gu, Y. Yan, Production and catalytic transformation of levulinic acid: a platform for speciality chemicals and fuels, Renewable Sustainable Energy Rev. 51 (2015) 986-997.

[57] J.-P. Lange, E. van der Heide, J. van Buijtenen, R. Price, Furfural-a promising platform for lignocellulosic biofuels, ChemSusChem 5 (2012) 150-166, http://dx.doi.org/10.1002/cssc.201100648.

[58] S. Peleteiro, S. Rivas, J.L. Alonso, V. Santos, J.C. Parajó, Furfural production using ionic liquids: a review, Bioresour. Technol. 202 (2016) 181-191, http://dx doi.org/10.1016/j.biortech.2015,12.017.

[59] B. Danon, G. Marcotullio, W. de Jong, Mechanistic and kinetic aspects of pentose dehydration towards furfural in aqueous media employing homogeneous catalysis, Green Chem. 16 (2014) 39-54, http://dx.doi.org/10. 1039/C3GC41351A.

[60] A. Mamman, J.-M. Lee, Y.-C. Kim, I. Hwang, N.-J. Park, Y. Hwang, J.S. Chang, J.-S. Hwang, No Title, Biofuels, Bioprod. Biorefin. 2 (2008) 438-454.

[61] I. Agirrezabal-Telleria, I. Gandarias, P.L. Arias, Heterogeneous acid-catalysts for the production of furan-derived compounds (furfural and hydroxymethylfurfural) from renewable carbohydrates: a review, Catal. Today 234 (2014) 42-58, http://dx.doi.org/10.1016/j.cattod.2013.11.02.

[62] J. Gravitis, N. Vedernikov, J. Zandersons, A. Kokorevics, Furfural and levoglucosan production from deciduous wood and agricultural wastes, Chem. Mater. (2001) 110-122, http://dx.doi.org/10.1021/bk-20010784ch009, Renew. Resources, ACS Symposium Series.

[63] D. Montané, J. Salvadó, C. Torras, X. Farriol, High-temperature dilute-acid hydrolysis of olive stones for furfural production, Biomass Bioenergy 22 (2002) 295-304, http://dx.doi.org/10.1016/S0961-9534(02)00007-7.

[64] K.J. Zeitsch, The Chemistry and Technology of Furfural and its Many By-products, first ed., Elsevier, The Netherlands, 2000.

[65] M.J. Antal, T. Leesomboon, W.S. Mok, G.N. Richards, Mechanism of formation of 2-furaldehyde from D-xylose, Carbohydr. Res. 217 (1991) 71-85, http:// dx.doi.org/10.1016/0008-6215(91)84118-X.

[66] T. Ahmad, L. Kenne, K. Olsson, O. Theander, The formation of 2-furaldehyde and formic acid from pentoses in slightly acidic deuterium oxide studied by 1H NMR spectroscopy, Carbohydr. Res. 276 (1995) 309-320, http://dx.doi. org/10.1016/0008-6215(95)00176-T.

[67] M.S. Feather, D.W. Harris, S.B. Nichols, Routes of conversion of D-xylose, hexuronic acids, and L-ascorbic acid to 2-furaldehyde, J. Org. Chem. 37 (1972) 1606-1608, http://dx.doi.org/10.1021/jo00975a032.

[68] W. de Jong, G. Marcotullio, Overview of biorefineries based on co-production of furfural, existing concepts and novel developments, Int. J. Chem. React. Eng. 8 (2010), http://dx.doi.org/10.2202/1542-6580.2174.
[69] R. Suxia, X. Haiyan, Z. Jinling, L. Shunqing, H. Xiaofeng, L. Tingzhou, Furfural production from rice husk using sulfuric acid and a solid acid catalyst through a two-stage process, Carbohydr. Res. 359 (2012) 1-6, http://dx.doi. org/10.1016/j.carres.2012.07.006.

[70] T. Marzialetti, M.B. Valenzuela Olarte, C. Sievers, T.J.C. Hoskins, P.K. Agrawal, C.W. Jones, Dilute acid hydrolysis of loblolly pine: a comprehensive approach, Ind. Eng. Chem. Res. 47 (2008) 7131-7140, http://dx.doi.org/10. 1021/ie800455f.

[71] B.M. Barbosa, J.L. Colodette, D. Longue Júnior, F.J.B. Gomes, D.C. Martino, Preliminary studies on furfural production from lignocellulosics, J. Wood Chem. Technol. 34 (2014) 178-190, http://dx.doi.org/10.1080/02773813. 2013.844167.

[72] M. Vázquez, M. Oliva, S.J. Téllez-Luis, J.A. Ramírez, Hydrolysis of sorghum straw using phosphoric acid: evaluation of furfural production, Bioresour. Technol. 98 (2007) 3053-3060, http://dx.doi.org/10.1016/j.biortech.2006. 10.017.

[73] E.S. Kim, S. Liu, M.M. Abu-Omar, N.S. Mosier, Selective conversion of biomass hemicellulose to furfural using maleic acid with microwave heating, Energy Fuels 26 (2012) 1298-1304, http://dx.doi.org/10.1021/ef2014106.

[74] A.S. Dias, M. Pillinger, A.A. Valente, Liquid phase dehydration of D-xylose in the presence of Keggin-type heteropolyacids, Appl. Catal. A: Gen. 285 (2005) 126-131, http://dx.doi.org/10.1016/j.apcata.2005.02.016.

[75] V. Choudhary, S.I. Sandler, D.G. Vlachos, Conversion of xylose to furfural using Lewis and Brønsted acid catalysts in aqueous media, ACS Catal. 2 (2012) 2022-2028, http://dx.doi.org/10.1021/cs300265d.

[76] G. Marcotullio, W. De Jong, Chloride ions enhance furfural formation from D-xylose in dilute aqueous acidic solutions, Green Chem. 12 (2010) 1739, http://dx.doi.org/10.1039/b927424c.

[77] T. vom Stein, P.M. Grande, W. Leitner, P. Domínguez de María, Iron-catalyzed furfural production in biobased biphasic systems: from pure sugars to direct use of crude xylose effluents as feedstock, ChemSusChem 4 (2011) 1592-1594, http://dx.doi.org/10.1002/cssc.201100259.

[78] E.I. Gürbüz, S.G. Wettstein, J.A. Dumesic, Conversion of hemicellulose to furfural and levulinic acid using biphasic reactors with alkylphenol solvents, ChemSusChem 5 (2012) 383-387, http://dx.doi.org/10.1002/cssc. 201100608.

[79] M. Shirotori, S. Nishimura, K. Ebitani, One-pot synthesis of furfural derivatives from pentoses using solid acid and base catalysts, Catal. Sci. Technol. 4 (2014) 971, http://dx.doi.org/10.1039/c3cy00980g.

[80] C. Moreau, R. Durand, D. Peyron, J. Duhamet, P. Rivalier, Selective preparation of furfural from xylose over microporous solid acid catalysts, Ind. Crops Prod. 7 (1998) 95-99, http://dx.doi.org/10.1016/S09266690(97)00037-X

[81] S.M. Bruce, Z. Zong, A. Chatzidimitriou, L.E. Avci, J.Q. Bond, M.A. Carreon, S.G. Wettstein, Small pore zeolite catalysts for furfural synthesis from xylose and switchgrass in $\gamma$-valerolactone/water solvent, J. Mol. Catal. A: Chem. 422 (2016) 18-22 http://dx.doi.org/10.106/j.molcata.2016.02.025.

[82] J. Lessard, J.-F. Morin, J.-F. Wehrung, D. Magnin, E. Chornet, High yield conversion of residual pentoses into furfural via zeolite catalysis and catalytic hydrogenation of furfural to 2-methylfuran, Top. Catal. 53 (2010) 1231-1234, http://dx.doi.org/10.1007/s11244-010-9568-7.

[83] R. O'Neill, M.N. Ahmad, L. Vanoye, F. Aiouache, Kinetics of aqueous phase dehydration of xylose into furfural catalyzed by ZSM-5 zeolite, Ind. Eng. Chem. Res. 48 (2009) 4300-4306, http://dx.doi.org/10.1021/ie801599k.

[84] S.B. Kim, S.J. You, Y.T. Kim, S. Lee, H. Lee, K. Park, E.D. Park, Dehydration of D-xylose into furfural over H-zeolites, Korean J. Chem. Eng. 28 (2011) 710-716, http://dx.doi.org/10.1007/s11814-010-0417-y.

[85] S. Lima, M. Pillinger, A.A. Valente, Dehydration of d-xylose into furfural catalysed by solid acids derived from the layered zeolite Nu-6(1), Catal. Comm. 9 (2008), http://dx.doi.org/10.1016/j.catcom.2008.04.016.

[86] S. Lima, A. Fernandes, M.M. Antunes, M. Pillinger, F. Ribeiro, A.A. Valente, Dehydration of xylose into furfural in the presence of crystalline microporous silicoaluminophosphates, Catal. Lett. 135 (2010) 41-47, http:// dx.doi.org/10.1007/s10562-010-0259-6.

[87] P. Bhaumik, P.L. Dhepe, Effects of careful designing of SAPO-44 catalysts on the efficient synthesis of furfural, Catal. Today 251 (2015) 66-72, http://dx. doi.org/10.1016/j.cattod.2014.10.042.

[88] M.M. Antunes, S. Lima, A. Fernandes, M. Pillinger, M.F. Ribeiro, A.A. Valente, Aqueous-phase dehydration of xylose to furfural in the presence of MCM-22 and ITQ-2 solid acid catalysts, Appl. Catal. A: Gen. 417 (2012) 243-252, http://dx.doi.org/10.1016/j.apcata.2011.12.046.

[89] X. Shi, Y. Wu, H. Yi, G. Rui, P. Li, M. Yang, G. Wang, Selective preparation of furfural from xylose over sulfonic acid functionalized mesoporous Sba-15 materials, Energies 4 (2011) 669-684, http://dx.doi.org/10.3390/en4040669.

[90] J. Zhang, J. Zhuang, L. Lin, Z. Zhang, Conversion of D-xylose into furfural with mesoporous molecular sieve MCM-41 as catalyst and butanol as the extraction phase, Biomass Bioenergy 39 (2012) 73-77, http://dx.doi.org/10. 1016/j.biombioe.2010.07.028.

[91] A.S. Dias, M. Pillinger, A.A. Valente, Dehydration of xylose into furfural over micro-mesoporous sulfonic acid catalysts, J. Catal. 229 (2005) 414-423, http://dx.doi.org/10.1016/j.jcat.2004.11.016.

[92] C. Moreau, R. Durand, S. Razigade, J. Duhamet, P. Faugeras, P. Rivalier, P. Ros, G. Avignon, Dehydration of fructose to 5-hydroxymethylfurfural over H-mordenites, Appl. Catal. A: Gen. 145 (1996) 211-224, http://dx.doi.org/ 10.1016/0926-860X(96)00136-6. 
[93] X. Li, P. Jia, T. Wang, Furfural: a promising platform compound for sustainable production of C 4 and C 5 chemicals, ACS Catal. (2016) 7621-7640, http://dx.doi.org/10.1021/acscatal.6b01838.

[94] I. Agirrezabal-Telleria, J. Requies, M.B. Güemez, P.L. Arias, Pore size tuning of functionalized SBA-15 catalysts for the selective production of furfural from xylose, Appl. Catal. B: Environ. 115 (2012) 169-178, http://dx.doi.org/10. 1016/j.apcatb.2011.12.025.

[95] I. Agirrezabal-Telleria, J. Requies, M.B. Güemez, P.L. Arias, Dehydration of D-xylose to furfural using selective and hydrothermally stable arenesulfonic SBA-15 catalysts, Appl. Catal. B: Environ. 145 (2014) 34-42, http://dx.doi. org/10.1016/j.apcatb.2012.11.010.

[96] I. Agirrezabal-Telleria, C. García-Sancho, P. Maireles-Torres, P.L. Arias, Dehydration of xylose to furfural using a Lewis or Brønsted acid catalyst and N 2 stripping, Chin. J. Catal. 34 (2013) 1402-1406, http://dx.doi.org/10.1016/ S1872-2067(12)60599-3.

[97] Z. Xu, W. Li, Z. Du, H. Wu, H. Jameel, H. Chang, L. Ma, Conversion of corn stalk into furfural using a novel heterogeneous strong acid catalyst in $\gamma$-valerolactone, Bioresour. Technol. 198 (2015) 764-771, http://dx.doi.org/ 10.1016/j.biortech.2015.09.104.

[98] P.L. Dhepe, R. Sahu, A solid-acid-based process for the conversion of hemicellulose, Green Chem. 12 (2010) 2153, http://dx.doi.org/10.1039/ c004128a.

[99] A. Chareonlimkun, V. Champreda, A. Shotipruk, N. Laosiripojana, Catalytic conversion of sugarcane bagasse, rice husk and corncob in the presence of $\mathrm{TiO}_{2}, \mathrm{ZrO}_{2}$ and mixed-oxide $\mathrm{TiO}_{2}-\mathrm{ZrO}_{2}$ under hot compressed water (HCW) condition, Bioresour. Technol. 101 (2010) 4179-4186, http://dx.doi.org/10. 1016/j.biortech.2010.01.037

[100] P. Zhou, Z. Zhang, One-pot catalytic conversion of carbohydrates into furfural and 5-hydroxymethylfurfural, Catal. Sci. Technol. 6 (2016) 3694-3712, http://dx.doi.org/10.1039/C6CY00384B.

[101] L. Zhang, G. Xi, Z. Chen, D. Jiang, H. Yu, X. Wang, Highly selective conversion of glucose into furfural over modified zeolites, Chem. Eng. J. 307 (2017) 868-876, http://dx.doi.org/10.1016/j.cej.2016.09.001

[102] V. Heguaburu, J. Franco, L. Reina, C. Tabarez, G. Moyna, P. Moyna, Dehydration of carbohydrates to 2-furaldehydes in ionic liquids by catalysis with ion exchange resins, Catal. Commun. 27 (2012) 88-91, http://dx.doi. org/10.1016/j.catcom.2012.07.002.

[103] L. Zhang, H. Yu, P. Wang, H. Dong, X. Peng, Conversion of xylan, D-xylose and lignocellulosic biomass into furfural using $\mathrm{AlCl} 3$ as catalyst in ionic liquid, Bioresour. Technol. 130 (2013) 110-116, http://dx.doi.org/10.1016/j. biortech.2012.12.018.

[104] Z. Zhang, Z.K. Zhao, Microwave-assisted conversion of lignocellulosic biomass into furans in ionic liquid, Bioresour. Technol. 101 (2010) 1111-1114, http://dx.doi.org/10.1016/j.biortech.2009.09.010.

[105] L. Zhang, H. Yu, P. Wang, Solid acids as catalysts for the conversion of D-xylose, xylan and lignocellulosics into furfural in ionic liquid, Bioresour. Technol. 136 (2013) 515-521, http://dx.doi.org/10.1016/j.biortech.2013.03. 054.

[106] Z. Zhang, B. Du, Z.J. Quan, Y.X. Da, X.C. Wang, Dehydration of biomass to furfural catalyzed by reusable polymer bound sulfonic acid (PEG-OSO3H) in ionic liquid, Catal. Sci. Technol. 4 (2014) 633-638, http://dx.doi.org/10.1039/ c3cy00888f.

[107] S. Lima, P. Neves, M.M. Antunes, M. Pillinger, N. Ignatyev, A.A. Valente, Conversion of mono/di/polysaccharides into furan compounds using 1-alkyl-3-methylimidazolium ionic liquids, Appl. Catal. A: Gen. 363 (2009) 93-99, http://dx.doi.org/10.1016/j.apcata.2009.04.049.

[108] S. Peleteiro, A.M. Da Costa Lopes, G. Garrote, R. Bogel-Łukasik, J.C. Parajó, Manufacture of furfural in biphasic media made up of an ionic liquid and a co-solvent, Ind. Crops Prod. 77 (2015) 163-166, http://dx.doi.org/10.1016/j. indcrop.2015.08.048.

[109] A. Brandt, M.J. Ray, T.Q. To, D.J. Leak, R.J. Murphy, T. Welton, Ionic liquid pretreatment of lignocellulosic biomass with ionic liquid-water mixtures, Green Chem. 13 (2011) 2489-2499, http://dx.doi.org/10.1039/C1GC15374A.

[110] A.V. Carvalho, A.M. da Costa Lopes, R. Bogel-Łukasik, Relevance of the acidic 1-butyl-3-methylimidazolium hydrogen sulphate ionic liquid in the selective catalysis of the biomass hemicellulose fraction, RSC Adv. 5 (2015) 47153-47164, http://dx.doi.org/10.1039/C5RA07159C.

[111] F.A.H. Rice, Effect of aqueous sulfuric acid on reducing sugars. V. Infrared studies on the humins formed by the action of aqueous sulfuric acid on the aldopentoses and on the aldehydes derived from them, J. Org. Chem. 23 (1958) 465-468, http://dx.doi.org/10.1021/jo01097a036.

[112] T.M.C. Hoang, L. Lefferts, K. Seshan, Valorization of humin-based byproducts from biomass processing-a route to sustainable hydrogen, ChemSusChem 6 (2013) 1651-1658, http://dx.doi.org/10.1002/cssc.201300446.

[113] I.V. Sumerskii, S.M. Krutov, M.Y. Zarubin, Humin-like substances formed under the conditions of industrial hydrolysis of wood, Russ. J. Appl. Chem. 83 (2010) 320-327, http://dx.doi.org/10.1134/S1070427210020266.

[114] M. Sevilla, A.B. Fuertes, Chemical and structural properties of carbonaceous products obtained by hydrothermal carbonization of saccharides, Chem.-Eur. J. 15 (2009) 4195-4203, http://dx.doi.org/10.1002/chem. 200802097

[115] M. Sevilla, A.B. Fuertes, The production of carbon materials by hydrotherma carbonization of cellulose, Carbon N. Y. 47 (2009) 2281-2289, http://dx.doi. org/10.1016/j.carbon.2009.04.026.

[116] I. van Zandvoort, Y. Wang, C.B. Rasrendra, E.R.H. van Eck, P.C.A. Bruijnincx, H.J. Heeres, B.M. Weckhuysen, Formation, molecular structure, and morphology of humins in biomass conversion: influence of feedstock and processing conditions, ChemSusChem 6 (2013) 1745-1758, http://dx.doi. org/10.1002/cssc.201300332.

[117] G. Tsilomelekis, M.J. Orella, Z. Lin, Z. Cheng, W. Zheng, V. Nikolakis, D.G. Vlachos, Molecular structure, morphology and growth mechanisms and rates of 5-hydroxymethyl furfural (HMF) derived humins, Green Chem. 18 (2016) 1983-1993, http://dx.doi.org/10.1039/C5GC01938A.

[118] S.K.R. Patil, J. Heltzel, C.R.F. Lund, Comparison of structural features of humins formed catalytically from glucose, fructose, and 5-hydroxymethylfurfuraldehyde, Energy Fuels 26 (2012) 5281-5293, http:// dx.doi.org/10.1021/ef3007454.

[119] K. Lamminpää, J. Ahola, J. Tanskanen, Kinetics of furfural destruction in a formic acid medium, RSC Adv. 4 (2014) 60243-60248, http://dx.doi.org/10. 1039/C4RA09276G.

[120] B. Danon, L. van der Aa, W. de Jong, Furfural degradation in a dilute acidic and saline solution in the presence of glucose, Carbohydr. Res. 375 (2013) 145-152, http://dx.doi.org/10.1016/j.carres.2013.04.030.

[121] R. Weingarten, J. Cho, W.C. Conner Jr., G.W. Huber, Kinetics of furfural production by dehydration of xylose in a biphasic reactor with microwave heating, Green Chem. 12 (2010) 1423, http://dx.doi.org/10.1039/c003459b.

[122] B. Girisuta, L.P.B.M. Janssen, H.J. Heeres, Green chemicals: a kinetic study on the conversion of glucose to levulinic acid, Chem. Eng. Res. Des. 84 (2006) 339-349, http://dx.doi.org/10.1205/cherd05038.

[123] T. Eifert, M.A. Liauw, Process analytical technology (PAT) applied to biomass valorisation: a kinetic study on the multiphase dehydration of xylose to furfural, React. Chem. Eng. 1 (2016) 521-532, http://dx.doi.org/10.1039/ C6RE00082G.

[124] F. Stankovikj, A.G. McDonald, G.L. Helms, M. Garcia-Perez, Quantification of bio-oil functional groups and evidences of the presence of pyrolytic humins, Energy Fuels 30 (2016) 6505-6524, http://dx.doi.org/10.1021/acs. energyfuels.6b01242.

[125] J. Horvat, B. Klaić, B. Metelko, V. Šunjić, Mechanism of levulinic acid formation, Tetrahedron Lett. 26 (1985) 2111-2114, http://dx.doi.org/10. 1016/S0040-4039(00)94793-2.

[126] S.K.R. Patil, C.R.F. Lund, Formation and growth of humins via aldol addition and condensation during acid-catalyzed conversion of 5-hydroxymethylfurfural, Energy Fuels (2011), http://dx.doi.org/10.1021/ ef2010157.

[127] F. Ilgen, D. Ott, D. Kralisch, C. Reil, A. Palmberger, B. Konig, Conversion of carbohydrates into 5-hydroxymethylfurfural in highly concentrated low melting mixtures, Green Chem. 11 (2009) 1948-1954, http://dx.doi.org/10. 1039/B917548M.

[128] G.W. Huber, J.A. Dumesic, An overview of aqueous-phase catalytic processes for production of hydrogen and alkanes in a biorefinery, Catal. Today 111 (2006) 119-132, http://dx.doi.org/10.1016/j.cattod.2005.10.010.

[129] S.J. Dee, A.T. Bell, A study of the acid-catalyzed hydrolysis of cellulose dissolved in ionic liquids and the factors influencing the dehydration of glucose and the formation of humins, ChemSusChem 4 (2011) 1166-1173, http://dx.doi.org/10.1002/cssc.201000426.

[130] J. Herzfeld, D. Rand, Y. Matsuki, E. Daviso, M. Mak-Jurkauskas, I. Mamajanov, Molecular structure of humin and melanoidin via solid state NMR, J. Phys. Chem. B 115 (2011) 5741-5745, http://dx.doi.org/10.1021/jp1119662.

[131] G.R. Akien, L. Oi, I.T. Horváth, Molecular mapping of the acid catalysed dehydration of fructose, Chem. Commun. 48 (2012) 5850, http://dx.doi.org/ 10.1039/c2cc31689g.

[132] A. Gandini, M.N. Belgacem, Furans in polymer chemistry, Prog. Polym. Sci. 22 (1997) 1203-1379, http://dx.doi.org/10.1016/S0079-6700(97)00004-X.

[133] I. van Zandvoort, E.R.H. van Eck, P. de Peinder, H.J. Heeres, P.C.A. Bruijnincx, B.M. Weckhuysen, Full, reactive solubilization of humin byproducts by alkaline treatment and characterization of the alkali-treated humins formed, ACS Sustain. Chem. Eng. 3 (2015) 533-543, http://dx.doi.org/10. 1021/sc500772w

[134] S. Wang, H. Lin, Y. Zhao, J. Chen, J. Zhou, Structural characterization and pyrolysis behavior of humin by-products from the acid-catalyzed conversion of C6 and C5 carbohydrates, J. Anal. Appl. Pyrolysis 118 (2016) 259-266, http://dx.doi.org/10.1016/j.jaap.2016.02.009.

[135] X. Tang, Y. Sun, X. Zeng, W. Hao, L. Lin, S. Liu, Novel process for the extraction of ethyl levulinate by toluene with less humins from the ethanolysis products of carbohydrates, Energy Fuels 28 (2014) 4251-4255, http://dx.doi.org/10.1021/ef5000497.

[136] J.-P. Lange, Renewable feedstocks: the problem of catalyst deactivation and its mitigation, Angew. Chem. Int. Ed. 54 (2015) 13186-13197, http://dx.doi. org/10.1002/anie.201503595.

[137] K.L. von Hebel, J.-P. Lange, Process for liquefying a cellulosic material and its products, WO/20110277378, 2011.

[138] D.M. Alonso, S.G. Wettstein, M.A. Mellmer, E.I. Gurbuz, J.A. Dumesic, Integrated conversion of hemicellulose and cellulose from lignocellulosic biomass, Energy Environ. Sci. 6 (2013) 76-80, http://dx.doi.org/10.1039/ C2EE23617F.

[139] J. Byun, J. Han, Catalytic production of biofuels (butene oligomers) and biochemicals (tetrahydrofurfuryl alcohol) from corn stover, Bioresour. Technol. 211 (2016) 360-366, http://dx.doi.org/10.1016/j.biortech.2016.03. 123.

[140] J.-M. Pin, N. Guigo, A. Mija, L. Vincent, N. Sbirrazzuoli, J.C. van der Waal, E. de Jong, Valorization of biorefinery side-stream products: combination of 
humins with polyfurfuryl alcohol for composite elaboration, ACS Sustain. Chem. Eng. 2 (2014) 2182-2190, http://dx.doi.org/10.1021/sc5003769.

[141] C.B. Rasrendra, M. Windt, Y. Wang, S. Adisasmito, I.G.B.N. Makertihartha, E.R.H. Van Eck, D. Meier, H.J. Heeres, Experimental studies on the pyrolysis of humins from the acid-catalysed dehydration of C6-sugars, J. Anal. Appl. Pyrolysis (2013), http://dx.doi.org/10.1016/j.jaap.2013.07.003.
[142] Y. Wang, S. Agarwal, A. Kloekhorst, H.J. Heeres, Catalytic hydrotreatment of humins in mixtures of formic acid/2-propanol with supported ruthenium catalysts, ChemSusChem 9 (2016) 951-961, http://dx.doi.org/10.1002/cssc. 201501371.

Please cite this article in press as: L. Filiciotto, et al., Catalytic insights into the production of biomass-derived side products methyl levulinate, furfural and humins, Catal. Today (2017), http://dx.doi.org/10.1016/j.cattod.2017.03.008 